(C) Dereito Vol.28, n02:163-199 (Xullo-Decembro, 2019) • ISSN 1132-9947

\title{
LITISPENDENCIA COMO CONDICIÓN DENEGATORIA DE RECONOCIMIENTO DE UNA RESOLUCIÓN EXTRANJERA
}

Lis pendens as a ground of non-recognition of a foreign judgment

DOI: http://dx.doi.org/10.15304/dereito.28.2.6177

\section{JAVIER MASEDA RODRÍGUEZ ${ }^{1}$}

Profesor Titular de Derecho Internacional Privado

Universidade de Santiago de Compostela

javier.maseda@usc.es

\section{Resumen}

Este trabajo tiene por objeto, al hilo de la STJUE de 16 de enero de 2019, Stefano Liberato $v$. Luminita Luisa Grigorescu, y en el marco de las disposiciones del Reglamento 2201/2003 y Reglamento 44/2001, determinar cómo afecta la infracción de las reglas de litispendencia internacional a la hora de valorar el reconocimiento de una resolución extranjera relativa a crisis matrimoniales, responsabilidad parental y obligaciones de alimentos emitida a partir del incumplimiento de tales reglas.

Palabras clave: Litispendencia; Reconocimiento; Condición denegatoria; Reglamento 2201/2003; Reglamento 44/2001.

\section{Abstract}

The purpose of this paper is to analyze briefly, in relationship of Judgement of the Court of 19 January 2019, Stefano Liberato v. Luminita Luisa Grigorescu, and within the framework of the provisions of Regulation (EC) 2201/2003 and Regulation (EC) 44/2001, how the infringement of the rules of international lis pendens affects the recognition and enforcement of a foreign judgment regarding matrimonial matters, matters of parental responsibility and matters relating to maintenance obligations issued from the breach of such rules.

Keywords: Lis pendens; Recognition; Grounds of non-recognition; Regulation (EC) 2201/2003; Regulation (EC) 44/2001.Lis pendens; Recognition; Grounds of non-recognition; Regulation (EC) 2201/2003; Regulation (EC) 44/2001.

\section{SUMARIO}

1.- INTRODUCCIÓN.; 1.1.- General.; 1.2.- Los hechos controvertidos.; 2.EXISTENCIA DE LITISPENDENCIA: ACTUACIÓN INCORRECTA DEL SEGUNDO DE LOS TRIBUNALES.; 2.1.- Litispendencia en materia de crisis matrimoniales, responsabilidad parental y alimentos.; 2.2.- Obligación de inhibición: actuación incorrecta del segundo Tribunal.; 2.2.1.- La

${ }^{1}$ ORCID ID: https://orcid.org/0000-0002-0601-8119

Recibido: 01/11/2019. Aceptado: 22/12/2019. 
declaración de competencia del primer Tribunal.; 2.2.2.- La competencia del primer Tribunal.; 2.2.3.- El error de los segundos Tribunales.; 3.RECONOCIMIENTO DE UNA RESOLUCIÓN EXTRANJERA E INFRACCIÓN DE LAS REGLAS DE LITISPENDENCIA: INTERACCIÓN.; 3.1.- La infracción de las reglas de litispendencia no es causa de denegación de reconocimiento.; 3.2.- Vinculación entre las reglas de litispendencia y las normas de competencia judicial internacional.; 3.3.- El orden público internacional y la quiebra de las reglas de litispendencia por parte del juez de origen.; 3.3.1.- En su proyección desde la competencia judicial internacional.; 3.3.2.- En su proyección desde el orden público procesal.; 4.- CONCLUSIONES.; 5.- BIBLIOGRAFÍA.

\section{SUMMARY}

1.-INTRODUCTION.; 1.1.- General.; 1.2.- The facts of the case.; 2.EXISTENCE OF LIS PENDENS: INCORRECT ACTION OF THE SECOND SEISED COURT.; 2.1.- Lis pendens in matrimonial matters, parental responsibility and maintenance obligations.; 2.2.- Obligation of declining jurisdiction: incorrect action of the second seised Court.; 2.2.1.- The establishment of jurisdiction of the first seised Court.; 2.2.2.- The jurisdiction of the first Court.; 2.2.3.- The error of the second Court.; 3.RECOGNITION OF A FOREIGN JUDGMENT AND INFRINGEMENT OF THE RULES OF LIS PENDENS: INTERACTION.; 3.1.- The infringement of the rules of lis pendens is not a reason for refusal of recognition.; 3.2.- Link between the rules of lis pendens and the rules of international jurisdiction.; 3.3.- The public policy and the breakdown of the rules of lis pendens by the judge of origin.; 3.3.1.- View from the international jurisdiction.; 3.3.2.- View from the procedural public policy.; 4.CONCLUSIONS.; 5.- BIBLIOGRAPHY.

\section{1.- INTRODUCCIÓN}

\section{1.- General}

Son muchos los problemas que plantea la convivencia entre una pluralidad de procesos en curso dirimidos ante las autoridades jurisdiccionales de diferentes Estados, o entre un proceso en curso ante los órganos jurisdiccionales de un Estado y la resolución emitida por el operador jurídico de otro Estado, a los que el legislador europeo, convencional o doméstico trata de responder con mayor o menor acierto. Sirva el caso de la Ley 29/2015, de 30 de julio, de cooperación jurídica internacional en materia civil2, cuyo art. 46.1.f LCJI establece que las resoluciones extranjeras firmes no se reconocerán cuando existiera un litigio pendiente en España entre las mismas partes y con el mismo objeto, iniciado con anterioridad al proceso en el extranjero: en parecidos términos que

\footnotetext{
*El presente trabajo se realizó en el marco de la estancia de investigación en el Institut suisse de droit comparé, Lausanne, Suiza (julio-2019). Agradezco al ISDC las facilidades que me proporcionaron durante este tiempo.

${ }^{2}$ Ley 29/2015, de 30 de julio, de cooperación jurídica internacional en materia civil (BOE de 31 de julio de 2015).
} 
muchos regímenes convencionales, viene el legislador español (y también el convencional) a conceder prioridad al proceso pendiente en el foro que es anterior a aquel proceso que dio lugar a la sentencia extranjera ya dictada ignorando la existencia previa de un proceso similar en otro Estado $^{3}$. Del mismo modo responde el legislador europeo, esta vez regulando en sede de reconocimiento la convivencia entre resoluciones ya dictadas más que la coexistencia entre una resolución ya dictada y un proceso pendiente, habida cuenta de la fortaleza que este legislador pretende imprimir a las reglas reguladoras de la litispendencia en orden a evitar la existencia de procesos paralelos, obligando al Tribunal ante el que se haya presentado la segunda de las demandas a inhibirse a favor del Tribunal ante el que se presentó la primera de ellas una vez establezca este último órgano su competencia ${ }^{4}$.

El trabajo que ahora nos ocupa tiene por objeto determinar, en este contexto y dentro de los límites de los instrumentos comunitarios, cómo afecta la infracción de las reglas de litispendencia internacional a la hora de valorar el reconocimiento de una resolución extranjera relativa a crisis matrimoniales, responsabilidad parental y obligaciones de alimentos emitida a partir del incumplimiento de tales reglas: en concreto, la posibilidad de denegar el reconocimiento de una resolución firme procedente de otro Estado miembro cuando los Tribunales de origen, ignorando la obligación de inhibirse impuesta por la normativa reguladora de la litispendencia, siguen conociendo del proceso que ha dado lugar a la resolución cuyo reconocimiento se pretende.

Objeto de una cuestión prejudicial elevada ante el Tribunal de Justicia de la Unión Europea (TJUE), se plantea esta problemática al hilo de un litigio relativo a una separación judicial y divorcio, a la responsabilidad parental y a obligaciones alimenticias respecto de menores, que enfrenta, por un lado, al Sr. Stefano Liberato, y, por otro, a la Sra. Luminita Luisa Grigorescu. A través de la STJUE de 16 de enero de 2019, Stefano

\footnotetext{
${ }^{3}$ Al respecto, véase, por todos, FERnÁndez RozAS, J.C./SÁnCHEZ LORENZO, S., Derecho internacional privado, 10 a ed., Civitas, Thomson Reuters, Madrid, 2018, pp. 281-284; o GASCÓn INCHAUSTI, F., "Reconocimiento y ejecución de resoluciones judiciales extranjeras en la Ley de cooperación jurídica internacional en materia civil", Cuadernos de Derecho Transnacional, núm. 2, 2015, pp. 158-187, espec. p. 183. En cualquier caso, en el ordenamiento jurídico español, no siempre la solución fue como la adoptada por este art. 46.1.f LCJI. Anteriormente, y en ausencia de respuesta explícita del legislador español, cierta práctica española llegó a priorizar el proceso pendiente en España aun cuando nacido con posterioridad al proceso que dio lugar a la sentencia extranjera cuyo reconocimiento se pretende en España (en este sentido, véase el ATS de 24 de abril de 1935, o ATS de 30 de septiembre de 1988), siendo por ello muy criticada en tanto que podía conformar un fraude al sistema (mejor, ATS de 20 de marzo de 2001, RJ 5520; sobre ello, REMIRo BRotóns, A., Ejecución de sentencias extranjeras en España (la jurisprudencia del Tribunal Supremo), Tecnos, Madrid, 1974, p. 253; o FERNÁNDEZ RozAS, J.C./SÁnCHEZ LoRENzo, S., Derecho internacional privado, $8^{a}$ ed., Civitas, Thomson Reuters, Madrid, 2015, p. 251.

${ }^{4}$ Al respecto, MalatestA, A., "Art. 19 R 2201", en Corneloup, S. (dir.), Droit européen du divorce. European Divorce Law, Université de Bourgogne, Lexis Nexis, Paris, 2013, pp. 321-338; respecto de la litispendencia en el Reglamento 1215/2012, DiCKINSON, A./LEIN, E. (ed.), The Brussels I Regulation Recast, Oxford, 2015, pp. 321-355.
} 
Liberato v. Luminita Luisa Grigorescu ${ }^{5}$, el TJUE se pronuncia sobre cómo valorar/proceder a la homologación de una resolución extranjera relativa a crisis matrimoniales y responsabilidad parental emitida a partir del incumplimiento del art. 19 del Reglamento (CE) núm. 2201/2003, del Consejo, de 27 de noviembre de 2003, relativo a la competencia, el reconocimiento y la ejecución de resoluciones judiciales en materia matrimonial y de responsabilidad parental ${ }^{6}$, y del art. 27 del Reglamento (CE) núm. 44/2001 del Consejo, de 22 de diciembre de 2000, relativo a la competencia judicial, el reconocimiento y la ejecución de resoluciones judiciales en materia civil y mercantil , reguladores de la litispendencia en estas materias.

Analizaremos, pues, la respuesta del TJUE a las cuestiones planteadas. En primer término, la existencia de una verdadera situación de litispendencia $y$, con ello, la correcta o incorrecta actuación de los Tribunales que emitieron la resolución a reconocer (punto II). Y, en segundo, la posibilidad de denegar el reconocimiento de una resolución firme dictada en violación de las reglas reguladoras de la litispendencia, valorando si cabe situar esta infracción en una o algunas de las causas de denegación de reconocimiento relacionadas en el régimen aplicable (punto III): por un lado, analizaremos las relaciones entre infracción de las reglas de litispendencia y control de competencia del juez de origen, tanto desde la óptica de art. 24 R. 2201 y 35 R. 44, como lo que es su proyección dentro de la figura del orden público; $y$, por otro, aspecto en el que no entró el TJUE en la resolución comentada, veremos si existen casos en los que una eventual infracción de las reglas de litispendencia sí pueda dar lugar a una vulneración del orden público internacional del Estado requerido.

Téngase en cuenta, en cualquier caso, que, aunque la cuestión prejudicial tiene su base en la aplicación del Reglamento 2201/2003, este instrumento resulta sólo aplicable a las cuestiones de estado civil y a la responsabilidad parental. No se aplica, no obstante, a las obligaciones alimenticias, cuya reclamación también es planteada en el litigo que nos ocupa tanto por el Sr. Liberato como por la Sra. Grigorescu. La Corte

\footnotetext{
${ }^{5}$ STJUE de 16 de enero de 2019, As. C-386/17, Stefano Liberato v. Luminita Luisa Grigorescu. Al respecto, Álvarez GonzÁlez, S., "Litispendencia, reconocimiento y orden público (Comentario breve a la Sentencia del Tribunal de Justicia de 16 de enero de 2019, Asunto C-386/17: Liberato), La Ley (Unión Europea), 29 de marzo de 2019, pp. 111.

${ }^{6}$ Reglamento (CE) núm. 2201/2003, del Consejo, de 27 de noviembre de 2003, relativo a la competencia, el reconocimiento y la ejecución de resoluciones judiciales en materia matrimonial y de responsabilidad parental (DOUE L 338/1, de 23 de diciembre de 2003). Se está trabajando en varias modificaciones en este Reglamento 2201/2003, que pueden consultarse en Propuesta de Reglamento del Consejo relativo a la competencia, el reconocimiento y la ejecución de resoluciones en materia matrimonial y de responsabilidad parental, y sobre la sustracción internacional de menores (refundición) (COM (2016) 411 Final).

${ }^{7}$ Reglamento (CE) núm. 44/2001, del Consejo, de 22 de diciembre de 2000, relativo a la competencia judicial, el reconocimiento y la ejecución de resoluciones judiciales en materia civil y mercantil (DOCE L núm. 12, de 16 de enero de 2001; corrección de errores en DOCE L 307, de 24 de noviembre de 2001 y DOCE L 176, de 5 de julio de 2002).
} 
suprema di cassazione italiana, como órgano jurisdiccional remitente, debería haberse referido al Reglamento 44/2001 (art. 5.2 R. 44), en tanto que instrumento aplicable a esta materia a las acciones interpuestas antes del 18 de junio de 2011, como son las que aquí nos ocupan ${ }^{8}$, fecha en la que deja de aplicarse el Reglamento 44/2001 para hacerlo el Reglamento (CE) núm. 4/2009 del Consejo, de 18 de diciembre de 2008, relativo a la competencia, la ley aplicable, el reconocimiento y la ejecución de las resoluciones y la cooperación en materia de obligaciones de alimentos ${ }^{9}$. Recuérdese que las obligaciones alimenticias venían siendo reguladas por el Convenio de Bruselas sobre competencia judicial y reconocimiento $y$ ejecución de decisiones en materia civil y mercantil, de 27 de septiembre de $1968^{10}$ e incluidas asimismo en el Reglamento 44/2001 dado su carácter de régimen sustituto del anterior, y ello, hasta la entrada en vigor el 30 de enero de 2009 y posterior aplicación a partir del 18 de junio de 2011 del Reglamento 4/2009, excluyéndose esta materia del ámbito de estos instrumentos, también del Reglamento (UE) núm. 1215/2012, del Parlamento Europeo y del Consejo, de 12 de diciembre de 2012, relativo a la competencia judicial, el reconocimiento y la ejecución de resoluciones judiciales en materia civil $y$ mercantil ${ }^{11}$ como régimen que sucedió después del 10 de enero de 2015 al Reglamento 44/2001 (art. 68 R. 4/2009) ${ }^{12}$.

\footnotetext{
${ }^{8}$ Como recuerda el Abogado General (par. 44, nota núm. 13), el Tribunale di Teramo (Italia) conoció de la demanda principal el 22 de mayo de 2007, ordenando el traslado para enjuiciar las reclamaciones dependientes mediante sentencia de 19 de enero de 2012 y pronunciándose por sentencia no definitiva de 8 de julio de 2013.

${ }^{9}$ Reglamento (CE) núm. 4/2009 del Consejo, de 18 de diciembre de 2008, relativo a la competencia, la ley aplicable, el reconocimiento y la ejecución de las resoluciones y la cooperación en materia de obligaciones de alimentos (DOUE de 10 de enero de 2009).

${ }^{10}$ Convenio de Bruselas sobre competencia judicial y reconocimiento y ejecución de decisiones en materia civil y mercantil, de 27 de septiembre de 1968 (DOCE C 189, de 28 de julio de 1990).

${ }^{11}$ Reglamento (UE) núm. 1215/2012, del Parlamento Europeo y del Consejo, de 12 de diciembre de 2012, relativo a la competencia judicial, el reconocimiento y la ejecución de resoluciones judiciales en materia civil y mercantil (DOCE L-351/1, de 20 de diciembre de 2012).

${ }^{12} \mathrm{El}$ art. 68 R. 4/2009 entiende que "...el presente Reglamento modifica al Reglamento (CE) núm. 44/2001 sustituyendo las disposiciones de dicho Reglamento aplicables en materia de obligaciones de alimentos...". Sobre ello, Álvarez GonzÁlez, S., "El Reglamento 4/2009/CE sobre obligaciones alimenticias: cuestiones escogidas", Diario La Ley, núm. 7230, 31 de julio de 2009, pp. 1-21, espec. par. II.2; o RoDRíGUEZ VÁzQUEZ, M.A., "La regulación del Reglamento 4/2009 en materia de obligaciones de alimentos: competencia judicial internacional, ley aplicable y reconocimiento y ejecución de sentencias", reei.org, vol. 19, 2010, pp. 1-30, espec. par. II.2, hablando de sustitución del Reglamento 44/2001 en esta materia (Considerando núm. 44 R. 4/2009) y no de modificación, aunque sea el término que emplea el art. 68 R. 4/2009. También, al respecto, véase la Propuesta de Reglamento del Consejo relativa a la competencia, la ley aplicable, el reconocimiento y la ejecución de las resoluciones y la cooperación en materia de obligaciones de alimentos (COM 2005649 final, 15 de diciembre de 2005); y la Comunicación de la Comisión al Consejo por la que se solicita al Consejo que las medidas adoptadas con arreglo al art. 65 del Tratado en materia de obligaciones de alimentos se rijan por el art. 251 del Tratado constitutivo de la Comunidad Europea (COM 2005, 648 final, 15 de diciembre de 2005).
} 
En cualquier caso, esta referencia de la Corte suprema di cassazione italiana en su cuestión prejudicial sólo al Reglamento 2201/2003 no va impedir, no obstante, que el TJUE se pronuncie (y su respuesta afecte) sobre la reclamación de alimentos, aun cuando incluida en un instrumento comunitario no referido por el órgano jurisdiccional remitente (FD 31$)^{13}$. Del mismo modo, aun cuando el órgano jurisdiccional remitente no menciona el art. 27 R. 44 y en tanto que este precepto, al igual que el art. 19 R. 2201, obligan al órgano jurisdiccional ante el que se interpuso la segunda demanda a inhibirse en favor del primer órgano jurisdiccional en caso de litispendencia, nada obsta a utilizar las consideraciones del TJUE relativas al art. 27 R. 44 (anterior art. 21 CB 1968) en relación con el art. 19 R. 2201 en atención a sus similitudes (FD 31 y 39) ${ }^{14}$.

$Y$ todo ello, no sin antes exponer sucintamente los hechos que generaron la controversia.

\section{2.- Los hechos controvertidos}

El 22 de octubre de 2005, contrajeron matrimonio en Roma (Italia) el Sr. Liberato y la Sra. Grigorescu. Allí vivieron juntos hasta el 20 de febrero de 2006, cuando tuvo lugar el nacimiento de su hijo. Surgidas desavenencias conyugales, la Sra. Grigorescu se trasladó con su hijo a Rumanía, no regresando al domicilio familiar en Italia.

El 22 de mayo de 2007, el Sr. Liberato presenta demanda de separación personal de la Sra. Grigorescu, además de reclamar la custodia del hijo, ante el Tribunale di Teramo (Italia). La Sra. Grigorescu, que compareció ante este Tribunal, solicitó la desestimación de esta demanda en cuanto al fondo (reclamó la separación, imputando la culpa al marido, además de la custodia exclusiva del hijo), presentando asimismo demanda reconvencional solicitando la contribución del padre a la manutención del hijo común. El Tribunale di Teramo determinó por sentencia de 19 de enero de 2012 la separación judicial de los cónyuges, atribuyendo la culpa a la Sra. Grigorescu, mientras que, a través de una resolución distinta (un auto separado), ordenó el traslado del asunto para su instrucción en relación con las reclamaciones contrapuestas en materia de responsabilidad parental.

Pendiente en Italia el procedimiento relativo a la responsabilidad parental, la Sra. Grigorescu solicitó el 30 de septiembre de 2009 ante la Judecătoria București (Tribunal de Primera Instancia de Bucarest, Rumanía), el divorcio, la custodia exclusiva del hijo menor, así como la contribución del padre a los alimentos del hijo. En vista de ello y con carácter preliminar, el

\footnotetext{
${ }^{13}$ Véase, al respecto y en este sentido, ap. 44 a 46 de la STJUE de 15 de febrero de 2017, As. C-499/15, $W$ y $V$, cuando estima que "...el hecho de que, en el plano formal, un órgano jurisdiccional nacional haya formulado una cuestión prejudicial refiriéndose a determinadas disposiciones del Derecho de la Unión no impide que el Tribunal de Justicia ofrezca a ese órgano jurisdiccional todas las interpretaciones que puedan serle útiles para juzgar el asunto de que conoce, haya o no hecho referencia a las mismas al formular sus cuestiones..."; también, ap. 43 de la STJUE de 29 de septiembre de 2016, As. C-492/14, Essent Belgium; o ap. 81 de la STJCE de 27 de octubre de 2009, As. C$115 / 08, C$ CEZ, y la jurisprudencia allí referida.

${ }^{14}$ Véase, en este sentido, ap. 27 de la STJUE de 6 de octubre de 2015, As. C- 489/14, A.
} 
Sr. Liberato, personándose ante este Tribunal, presentó la excepción de litispendencia basándose en que había incoado un procedimiento de separación y de responsabilidad parental en Italia en primer lugar. No obstante, la Judecătoria București dictó Sentencia de 31 de mayo de 2010 disolviendo el vínculo matrimonial, concediendo la custodia del hijo menor a la madre y determinando tanto el régimen de visitas del padre, como la cuantía de la pensión que este progenitor debía pagar al menor. Esta resolución adquirió fuerza de cosa juzgada una vez desestimado el recurso de apelación interpuesto por el Sr. Liberato ante el Tribunalul București (Tribunal de Distrito de Bucarest) por Sentencia de 3 de diciembre de 2012, confirmada por Sentencia de 12 de junio de 2013 de la Curtea de Apel București (Tribunal Superior de Bucarest).

Posteriormente, el Tribunale di Teramo remató el procedimiento de separación que se estaba dirimiendo en Italia por Sentencia de 8 de julio de 2013: concedió la custodia exclusiva del hijo menor al padre, ordenando el regreso del menor a Italia, y fijó el régimen de visitas de la madre en Italia, además de imponerle la obligación de contribuir a la manutención del hijo. Previamente, este mismo Tribunale di Teramo se había ocupado de desestimar la demanda incidental interpuesta por la Sra. Grigorescu y en la que se solicitaba el reconocimiento en Italia de la sentencia de divorcio dictada por el Tribunalul București el 3 de diciembre de 2012, en aplicación del Reglamento 2201/2003: apeló el Tribunale di Teramo a la infracción de art. 19 R. 2201, en tanto que el Tribunalul București no suspendió el procedimiento de divorcio iniciado en Rumanía aun cuando posterior (2009) al procedimiento de separación judicial incoado en Italia (2007).

La Sra. Grigorescu recurrió en apelación contra dicha sentencia, interponiendo, asimismo y con carácter preliminar, una demanda incidental en orden a reconocer la Sentencia de la Curtea de Apel București de 12 de junio de 2013, que desestimó la excepción de litispendencia basándose, según considera el órgano jurisdiccional remitente, en que los dos asuntos no tenían el mismo objeto de conformidad con el Derecho procesal rumano. Mediante sentencia de la Corte d'appello di L'Aquila de 31 de marzo de 2014, se modificó la sentencia dictada en primera instancia, estimándose la excepción relativa a la fuerza de cosa juzgada adquirida por la sentencia de divorcio dictada por los órganos jurisdiccionales rumanos, que tenía asimismo por objeto la custodia y alimentos del hijo menor: consideró que la infracción por parte de los órganos jurisdiccionales rumanos de las normas de litispendencia comunitarias no es "...pertinente..." a efectos del examen de los requisitos de reconocimiento de la resolución rumana, cuyas respuestas no son inconciliables con las dictadas en Italia, concluyendo la ausencia de motivos, en particular de orden público, que impidiesen el reconocimiento de la sentencia rumana.

En vista de ello, el Sr. Liberato interpuso recurso de casación contra esta resolución de la Corte d'appello di L'Aquila ante la Corte suprema di cassazione italiana, a la sazón, el órgano jurisdiccional remitente. El Alto Tribunal italiano considera que no existe ningún motivo basado en los 
distintos instrumentos comunitarios aplicables que justifique una oposición al reconocimiento de la sentencia rumana en lo que se refiere a los aspectos relativos al estado civil, a la responsabilidad parental y a las obligaciones alimenticias (art. 22.c y art. 23.e R. 2201; y art. 34.4 R. 44). Estima, no obstante, que los órganos jurisdiccionales rumanos sí han infringido las disposiciones comunitarias aplicables relativas a la litispendencia (arts. 19 R. 2201 y 27 R. 44), no estando legitimados para conocer de la controversia en tanto que segundos Tribunales (recuerda la Corte suprema que en el procedimiento de separación judicial incoado en Italia se habían formulado las mismas pretensiones, salvo en lo que se refiere a la relativa al vínculo matrimonial, que no era idéntica, puesto que el ordenamiento jurídico italiano exige que se acredite antes del divorcio el cumplimiento de las condiciones establecidas por la ley para la separación de los cónyuges), lo que llevó a la Corte suprema di cassazione italiana a cuestionarse si esta circunstancia puede constituir un motivo de denegación del reconocimiento, ubicable básicamente en el concepto de orden público internacional.

Por ello, decide formular una cuestión prejudicial ante el Tribunal de Justicia de la UE (TJUE) en orden a determinar si el art. 35.3 R. 44 y el art. 24 R. 2201 pueden interpretarse en el sentido de que no prohíben que la infracción de las normas de litispendencia del art. 27 R. 44 y 19 R. 2201 por parte del órgano jurisdiccional ante el que se interpuso la segunda demanda, pueda constituir un motivo de denegación del reconocimiento de la resolución dictada por este segundo Tribunal en atención a la contrariedad con el orden público del Estado miembro requerido en tanto que normas de procedimiento consideradas esenciales en el ordenamiento jurídico de la UE.

\section{2.- EXISTENCIA DE LITISPENDENCIA: ACTUACIÓN INCORRECTA DEL SEGUNDO DE LOS TRIBUNALES}

\section{1.- Litispendencia en materia de crisis matrimoniales, responsabilidad parental y alimentos}

No existe duda respecto de la vinculación entre ambos procesos y su traducción procesal como un supuesto de litispendencia. La relación existente entre la demanda de separación y custodia del menor interpuesta por el Sr. Liberato ante el Tribunale di Teramo, unida a la interpuesta ante este mismo Tribunal por la esposa relativa a la contribución de la manutención del hijo común, frente a aquélla otra de la esposa incoada ante la Judecătoria București, solicitando a su vez el divorcio, la custodia exclusiva del hijo menor, así como la contribución de cada progenitor a los alimentos del hijo, se sitúa en el concepto autónomo de litispendencia que maneja tanto el art. 19 R. 2201 como el art. 27 R. $44^{15}$, sin que obste a esta calificación la pluralidad de reclamaciones de cada demanda ubicables en regímenes aplicables diferentes ${ }^{16}$.

\footnotetext{
${ }^{15} \mathrm{Afirmando}$ la existencia de un concepto autónomo de litispendencia comunitaria, al margen del concepto de litispendencia que se utiliza en los distintos ordenamientos jurídicos nacionales de los Estados miembros, véase ap. 66 de la STJCE de 9 de
} 
Es lo que sucede en materia de obligaciones alimenticias entre la demanda "...incidental a la acción relativa al estado de las personas..." del art. 5.2 R. 44 dirimida en Italia y la reclamación de alimentos incoada ante los órganos jurisdiccionales rumanos. Idénticas las partes intervinientes, existe asimismo una identidad en el litigio dada la existencia de una misma causa y un mismo objeto ${ }^{17}$. Lo primero, en tanto que los litigios hacen referencia a los mismos hechos y las mismas normas jurídicas, si bien es cierto, no obstante, que una eventual utilización de diferentes normativas aplicables para fundamentar las pretensiones que se trate no debería suponer necesariamente una distinta identidad de acciones ${ }^{18}$. Y lo segundo, dada la identidad en la finalidad de las respectivas demandas, lo que incluye tanto los casos de identidad formal, como es el supuesto que nos ocupa, como aquéllos otros de identidad sustancial: recuérdese, a estos efectos, que la identidad no viene determinada por el petitum o la causa petendi, ni por la coincidencia del alcance de la cosa juzgada en ambas reclamaciones, sino por su sustancialidad, esto es, el hecho de estar discutiendo esencialmente lo mismo a riesgo de alcanzar resoluciones inconciliables ${ }^{19}$. Se verifican, así,

noviembre de 2010, As. C-296/10, Purrucker; o ap. 11 de la STJCE de 08 de diciembre de 1987, As. C-144/86, Gubisch Maschinenfabrik. En la doctrina, por todos, MAGNUS, U./MANkowski, P. (ed.), European Commentaries on Private International Law ECPIL: Brussels II bis Regulation, Sellier, Munich, 2012, p. 224; o GuZMÁn PECES, M., "Cuestiones problemáticas en torno a la litispendencia en el Reglamento (UE) 2201/2003 en el ámbito de las crisis familiares", La Ley (Unión Europea), de 28 de febrero de 2019, pp. 1-17, espec. par. 1. Por otra parte, en tanto que no existiría propiamente litispendencia, un Tribunal competente ex Reglamento 2201/2003 para una causa de divorcio no debe remitir el procedimiento a favor de otro Tribunal UE ante el que se está dirimiendo una causa de alimentos, aunque sea apropiado que ambas causas se resuelvan conjuntamente; al respecto, Ni ShúlleABáHIN, M., Cross-Border Divorce Law. Bruxelles II bis, Oxford University Press, 2010, pp. 211-214.

${ }^{16} \mathrm{El}$ ap. 36 de la resolución comentada, recurriendo a los ap. 56 y 57 de las Conclusiones del Abogado General, afirman que, "...si en el procedimiento relativo al vínculo matrimonial se presentan demandas relativas a la responsabilidad parental, se aplican las normas de la litispendencia relativas a la disolución matrimonial. Lo mismo cabe decir en materia de alimentos cuando las demandas sean incidentales a la acción relativa al estado de las personas, de conformidad con el artículo 5, punto 2, del Reglamento CE 44/2001. De ello se sigue que a las primeras demandas se les aplica el artículo 19, apartado 1, del Reglamento CE 2201/2003, mientras que las segundas se rigen por el artículo 27 del Reglamento 44/2001...". No entendemos esta afirmación del TJUE, más todavía cuando finalmente apela a las normas de litispendencia correspondientes a cada materia. Ofreciendo una posible explicación, véase ÁlvAREZ GonzÁlez, S., "Litispendencia...", loc. cit., par. 4.

${ }^{17}$ Así lo entiende, en materia de alimentos, el Abogado General, ap. 58 de sus Conclusiones.

${ }^{18}$ O'MALley, S./LAYTon, A., European civil practice, London, 1989, p. 632. Véase ap. 39 de la STJCE de 6 de diciembre de 1994, As. C-406/92, Tatry, que ha vinculado la identidad de causa a la atención a los mismos hechos y a la utilización de normas jurídicas semejantes a la hora de fundamentar la demanda.

${ }^{19}$ Virgós Soriano, M./Garcimartín AlfÉRez, F.J., Derecho procesal civil internacional (litigación internacional), $2^{a}$ ed., Madrid, 2007, p. 365; O'MALLEY, S./LAYTON, A., European..., op. cit., pp. 630-631. De este modo, existiría identidad formal entre una acción relativa a la declaración de no responsabilidad del demandante por los daños 
las exigencias del art. 27 R. 44 a la hora de poder apreciar litispendencia, que son los requisitos de identidad de objeto, partes y causa ${ }^{20}$, lo que se produce en este caso, como estamos viendo, y que se produciría, asimismo, de ubicarse este supuesto en el ámbito de aplicación temporal del Reglamento 4/2009, cuyo art. 12 R. 4/2009 recoge esencialmente las mismas soluciones ${ }^{21}$.

Lo expuesto es trasladable en materia de responsabilidad parental: existe litispendencia entre la demanda interpuesta en Italia por el Sr. Liberato y la interpuesta en Rumanía por su esposa en tanto que ambos solicitan la custodia exclusiva del hijo, conformando demandas con identidad de objeto y causa relativas a la responsabilidad parental sobre el mismo menor 22 .

Más matices, en cambio, cuando hablamos de crisis matrimoniales y la consideración del caso que nos ocupa como una situación de litispendencia intracomunitaria a pesar de que el Sr. Liberato haya solicitado la separación y la Sra. Grigorescu el divorcio ${ }^{23}$. Nada habría que decir

alegados por los demandados y la acción de los demandados dirigida a la declaración de responsabilidad y pago de perjuicios del demandante en el primer proceso, como sucede en la STJCE de 6 de diciembre de 1994, As. C-406/92, Tatry. Y existiría un caso de identidad sustancial entre una demanda de ejecución de un contrato de compraventa y aquélla otra dirigida hacia la resolución de dicho contrato, como resulta de la STJCE de 8 de diciembre de 1987, As. C-144/86, Gubisch Maschinenfabrik: detrás de cada una de las pretensiones y como núcleo litigioso, se halla la concreta existencia de las relaciones jurídicas contractuales entre acreedor y deudor, esto es, la fuerza obligatoria de dicho contrato (pretensión de su eficacia, por un lado, y negación de toda eficacia, por otro) (con dudas, Gaudemet-Tallon, H., Compétence et exécution des jugements en Europe (matières civile et commerciale: Règlements 44/2001 et 1215/2012, Conventions de Bruxelles 1968 et de Lugano 1988 et 2007), 5a ed., LGDJ, 2015, p. 433).

${ }^{20}$ Por todos, Virgós Soriano, M./Garcimartín AlfÉrez, F.J., Derecho procesal..., op. cit., pp. 365-370.

${ }^{21}$ Rodríguez VÁzQUEZ, M.A., "La regulación...", loc. cit., par. III.6. De hecho, en su Resolución de 13 de diciembre de 2007 (DOUE núm. C 323 E, de 18 de diciembre de 2008), el Parlamento Europeo propuso que los artículos sobre litispendencia y conexidad de lo que es el actual Reglamento 4/2009 podrían suprimirse y sustituirse por una referencia genérica al Reglamento 44/2001.

22Malatesta, A., "Art. 19 R 2201", en Corneloup, S. (dir.), Droit..., op. cit., p. 328; Virgós Soriano, M./Garcimartín AlfÉrez, F.J., Derecho procesal..., op. cit., p. 374; Magnus, U./MANKowski, P. (ed.), European..., op. cit., p. 233. Véase, sobre esta identidad, ap. 6768 de la STJUE de 9 de noviembre de 2010, As. C-296/10, Purrucker; o ap. 68-69 de STJUE de 22 de diciembre de 2010, As. C-497/10, Mercredi; o STS de 16 de diciembre de 2015 (RJ 2015\6185), respecto de un proceso de separación/divorcio promovido ante los Tribunales españoles y que resuelve asimismo cuestiones relativas a la responsabilidad parental, donde se cuestiona la existencia de litispendencia en este ámbito.

${ }^{23}$ Véase FD 35. A diferencia de regímenes como el Reglamento 1215/2012 (anterior Reglamento 44/2001), donde la relación entre sus normas de competencia judicial internacional es de jerarquía (así, Dickinson, A./LEIN, E. (ed.), The Brussels..., op. cit., pp. 113-311), en instrumentos como el Reglamento 2201/2003, en lo que respecta a crisis matrimoniales, la relación entre sus foros es de alternatividad (así, GAUDEMETTALLON, H., "Le Règlement no 1347/2000 du Conseil du 29 mai 2000: «Compétence, reconnaissance et exécution des décisions en matiere matrimoniale et en matiere de responsabilité parentale des enfants communs»", Journ. dr. int., 2001-II, pp. 381-430, espec. p. 395; Calvo Caravaca, A.L./Carrascosa González, J., Derecho internacional 
respecto de la existencia de una situación de litispendencia en aquellos casos en los que ambos cónyuges solicitasen lo mismo (la separación judicial, el divorcio o la nulidad), aun cuando su reclamación estuviese fundamentada en motivos diferentes ${ }^{24}$. Téngase en cuenta, no obstante, que son muchas las diferencias entre las legislaciones de los Estados de la UE en materia de separación judicial, divorcio y nulidad matrimonial, donde conviven Estados (Finlandia o Suecia, por ejemplo) que sólo legislan sobre el divorcio como único medio de disolución de un matrimonio y que desconocen figuras como la nulidad o la separación, con otros (España, por ejemplo), que regulan todas las instituciones, u otros, donde no existe la separación judicial (Alemania, por ejemplo) ${ }^{25}$.

Por ello, en relación con las demandas relativas a la disolución del vínculo matrimonial y en orden a valorar la existencia de un procedimiento concurrente, la única exigencia del art. 19.1 R. 2201, a diferencia de lo expuesto en relación con la responsabilidad parental del art. 19.2 R. 2201, tiene que ver con el hecho de que afecte a las partes (FD 35); o, lo que es lo mismo, "...puede existir una situación de litispendencia cuando [...] ante dos órganos jurisdiccionales de Estados miembros distintos se inician sendos procedimientos de separación y de divorcio, o cuando ante ambos órganos jurisdiccionales se inicia un procedimiento de divorcio..." ${ }^{26}$. No exigiendo que las demandas tengan el mismo objeto y la misma causa, sino que sean relativas a procedimientos de separación judicial, divorcio o

privado, vol, II, $15^{a}$ ed., Comares, Granada, 2014/2015, p. 192; SÁNCHEZ JimÉNEZ, M.A., El divorcio internacional en la Unión Europea (jurisdicción y ley aplicable), Cizur Menor (Navarra), Aranzadi Thomson Reuters, 2013, p. 33; en la práctica, por ejemplo, el $A A P$ Barcelona de 25 de julio de 2011, JUR 2011\307654, respecto de un divorcio entre cónyuges españoles con residencia habitual en Bolivia), de modo que son mucho mayores las probabilidades de que se planteen supuestos de litispendencia o conexidad ante Tribunales de Estados miembros distintos, disfrutando todos de competencia judicial internacional. Al respecto, BORRÁs RODRÍGUEZ, A.,"Informe explicativo del Convenio celebrado con arreglo al artículo K.3 del Tratado de la Unión Europea, sobre la competencia, el reconocimiento y la ejecución de resoluciones judiciales en materia matrimonial" (DOCE de 16 de julio de 1998, C 221, p. 27), p. 30; ANCEL, B./MUIR WATT, H., "La désunion européenne: le Réglement dit Bruxelles II", Rev. cr.. dr. int. pr., 2001, pp. 403-457, espec. p. 415 y pp. 428-429; GAUDEMET-TALLON, H., "Divorce - Divorce prononcé en France - Introduction - Compétence des tribunaux français - Particularités de I'instance", JurisClasseur - Droit international, fascículo 547-10, marzo de 2017, par. 133; Bonomi, A., "La compétence internationale en matière de divorce, quelques suggestions pour une (improbable) révision du règlement Bruxelles II bis", Rev. cr. dr. int. pr., 2017, pp. 511-534, espec. p. 514.

${ }^{24}$ GaUdemet-Tallon, H., "Le Règlement no 1347/2000...", loc. cit., pp. 400-401.

${ }^{25}$ Véase Borrás Rodríguez, A.,"Informe...", loc. cit., passim; MalatestA, A., "Art. 19 R 2201", en Corneloup, S. (dir.), Droit..., op. cit., p. 325.

${ }^{26}$ Véase ap. 33 de la STJUE de 6 de octubre de 2015, As. C- 489/14, A. También, STS de 16 de diciembre de 2015 (RAJ 2015\6185), entre una demanda de separación y divorcio ante los Tribunales españoles y una posterior solicitando el divorcio ante los Tribunales portugueses; SAP Barcelona de 29 de noviembre de 2011, entre dos demandas de divorcio, una, ante los Tribunales de París, y otra, ante los Tribunales de Barcelona; AAP Girona de 30 de julio de 2009 (JUR 2009\416732), entre dos demandas de divorcio ante Tribunales españoles e italianos; o AAP Tarragona de 25 de junio de 2009 (JUR 2009\426259), respecto de un divorcio entre cónyuges rumanos. 
nulidad matrimonial entre las mismas partes ${ }^{27}$, se consigue evitar la no apreciación de litispendencia por ausencia de objeto común cuando los petitum no coinciden formalmente aun cuando estén, por el contrario, indisolublemente unidos: son las llamadas acciones dependientes, de cuasi litispendencia o falsa litispendencia, esto es, procesos relativos a crisis matrimoniales cuyo vínculo se basa en una relación de dependencia o conexidad $^{28}$. De ahí también la existencia de un art. 19.3 R. 2201, cuando, en estos supuestos de acciones dependientes, permite a la parte actora en el segundo de los procesos presentar la acción ante el primero de los Tribunales, una vez que el segundo de ellos se inhibió a su favor ${ }^{29}$. Nada obsta, pues, a entender como una situación de litispendencia, en su calidad de acciones dependientes, la existente entre la demanda del Sr. Liberato solicitando la separación y aquélla otra interpuesta por la Sra. Grigorescu reclamando, esta vez, el divorcio.

\section{2.- Obligación de inhibición: actuación incorrecta del segundo Tribunal}

\subsection{1.- La declaración de competencia del primer Tribunal}

Verificada la relación de litispendencia entre ambos procesos, el art. 19 R. 2201 (al igual que el art. 27 R. 44, sustituido por el actual art. 12 R. 4/2009 en materia de obligaciones alimenticias) obliga a los órganos jurisdiccionales rumanos, como segundo de los Tribunales, a inhibirse a favor del Tribunal de Teramo como Tribunal ante el que se interpuso la primera demanda, en atención a la primacía del orden cronológico de las acciones ${ }^{30}$, y ello, una vez establecido "...que es competente el primer órgano jurisdiccional...", esto es, una vez suspendido "...de oficio el procedimiento en tanto no se establezca la competencia del órgano jurisdiccional ante el que se interpuso la primera (demanda)..."31.

\footnotetext{
27Virgós Soriano, M./Garcimartín AlfÉRez, F.J., Derecho procesal..., op. cit., p. 374; FERnÁNDEZ RozAS, J.C./SÁnCHEZ LORENZO, S., Derecho..., op. cit., 2018, pp. 477-478; CANO BAZAGA, E., "El Derecho de familia comunitario: competencia judicial internacional de los Tribunales españoles en materia de crisis matrimoniales y responsabilidad parental", Anuario de Derecho Europeo, núm. 2, 2002, pp. 67-89, espec. par. B.2; GAUDEMETTALLON, H., "Le Règlement no 1347/2000...", loc. cit., pp. 400-401.

${ }^{28}$ Sobre estos términos, BORRÁs ROdRÍGUEZ, A.,"Informe...", loc. cit., par. 54, en relación con el art. 11 R. 1347/2000, actual art. 19 R. 2201, exigiendo únicamente que las acciones relativas al divorcio, la nulidad matrimonial o la separación judicial sean formuladas entre las mismas partes, sin importar su situación procesal. También, CANO BAZAGA, E., "El Derecho...", loc. cit., par. B.2; asimismo, ANCEL, B./Muir WATT, M., "La désunion...", loc. cit., p. 415 y pp. 428-429.

${ }^{29}$ Sobre los problemas que puede plantear, por todos, BonOmI, A., "La compétence...", loc. cit., pp. 528-529.

${ }^{30}$ Véase ap. 30 de la STJUE de 6 de octubre de 2015, As. C-489/14, A. En la doctrina, Bonomi, A., "La compétence...", loc. cit., p. 528. Téngase en cuenta esta misma resolución STJUE de 6 de octubre de 2015, As. C-489/14, A., esta vez en el sentido de no considerar la existencia de litispendencia entre una primera demanda que decae en tanto que el demandante no realizó los actos necesarios para su notificación al demandado, de manera que la acción se extingue, pudiéndose, en consecuencia y dado que debe considerarse la competencia del primer Tribunal como "no establecida", continuar con la segunda de las demandas, que fue presentada posteriormente.

${ }^{31}$ Malatesta, A., "Art. 19 R 2201", en Corneloup, S. (dir.), Droit..., op. cit., pp. 331-333.
} 
No se cuestiona la declaración de competencia de los Tribunales italianos. En tal sentido y según se desprende de los autos del caso, consta tal declaración tanto para causa matrimonial como para la responsabilidad parental, esto es, se ha establecido la competencia del órgano jurisdiccional ante el que se interpuso la primera demanda. Tal es así en tanto que, en ausencia de manifestación expresa ${ }^{32}$, el Tribunal italiano no ha "...declinado de oficio su competencia y ninguna de las partes ha(ya) impugnado tal competencia con anterioridad o en el momento de la actuación procesal que el Derecho nacional considere como el primer medio de defensa en cuanto al fondo presentado ante dicho Tribunal..."33. 0 , lo que es lo mismo, no consta que el órgano jurisdiccional ante el que se interpuso la primera demanda haya declinado su competencia, tras haberla verificado obligatoriamente de conformidad con el art. 17 R. 2201 en cada etapa del procedimiento. Téngase en cuenta, en lo que respecta a la reclamación relativa a la responsabilidad parental ante los Tribunales italianos, que la prórroga de la competencia del art. 12.1 R. 2201 supone la ausencia de impugnación por parte de la madre de la competencia del órgano jurisdiccional italiano, verificando éste, asimismo, que su correspondencia con el interés superior del menor ${ }^{34}$.

Los distintos instrumentos comunitarios no determinan cuándo ha de considerarse que el Tribunal ante el que se interpuso la primera demanda se ha declarado competente a efectos de sus preceptos relativos al tratamiento de la litispendencia. De no comparecer el demandado emplazado en debida forma, el órgano jurisdiccional italiano debe verificar de oficio su competencia (art. 17 R. 2201), aclarando la resolución que resuelve esta verificación la postura del Tribunal rumano ex art. 19.3 R.2201: levantar la suspensión y conocer, de abstenerse el primer Tribunal (y correspondiente sobreseimiento del proceso) por incompetencia; o bien inhibirse a favor del Tribunal italiano, si no se abstiene, lo que supondría implícita o explícitamente la declaración de su competencia, en tanto que ya ha transcurrido el momento procesal oportuno en el que se podría

\footnotetext{
${ }^{32}$ Véase ap. 49 (nota núm. 20) de las Conclusiones del Abogado General.

${ }^{33} \mathrm{Al}$ respecto, ap. 34 de la STJUE de 6 de octubre de 2015, As. C- 489/14, A., en atención, por analogía, del ap. 44 de la STJUE de 27 de febrero de 2014, As. C-1/13, Cartier, que así se manifestó en relación con el art. 27 R. 44 (actual art. 29 R. 1215) y cuyas conclusiones pueden extenderse al art. 19.2 R. 2201. Véase, asimismo, el ap. 81 de la STJCE de 9 de noviembre de 2010, As. C-296/10, Purrucker, al establecer que, "...cuando los dos litigios enfrenten a las mismas partes, el segundo órgano jurisdiccional podrá interrogar a la parte que propone la excepción de litispendencia acerca de la existencia del litigio alegado y del contenido de la demanda. Por otra parte, teniendo en cuenta que el Reglamento 2201/2003 se fundamenta sobre la cooperación y la confianza mutua entre órganos jurisdiccionales, este órgano jurisdiccional podrá advertir al primero de que ante él se ha interpuesto una demanda, llamar la atención de este último sobre la eventualidad de una litispendencia, invitarlo a que le informe acerca de la demanda pendiente ante él y a que se pronuncie acerca de su competencia, en el sentido del Reglamento 2201/2003, o le comunique toda resolución ya adoptada a este respecto. Finalmente, el órgano jurisdiccional ante el que se plantea el asunto en segundo lugar podrá dirigirse a la autoridad central de su Estado miembro...".

${ }^{34}$ Respecto del interés superior del menor, véase ap. 44 de la STJUE de 01 de octubre de 2014, As. C-436/13, E. Sobre las exigencias relativas al art. 12 R. 2201, ap. 23, 24, 33 y 35 de la STJUE de 19 de abril de 2018, As. C-565/16, Saponaro y Xylina.
} 
cuestionar la competencia. De haber comparecido la Sra. Grigorescu para proponer la excepción de falta de competencia, el Tribunal italiano resolvería a través del equivalente en su Derecho procesal interno a la declinatoria internacional del Derecho español (arts. 39 y 63 y ss LEC): se declararía competente o incompetente, vinculando esta decisión a los Tribunales rumanos a efectos del art. 19.3 R. 2201. Lo que hizo la Sra. Grigorescu, no obstante, fue personarse en el procedimiento ante los Tribunales de Teramo para solicitar la desestimación de la demanda en cuanto al fondo (separación y custodia exclusiva del hijo) y demanda reconvencional relativa a la contribución del padre a la manutención del hijo, lo que procesalmente podría traducirse como una regla de preclusión de la excepción de falta de competencia judicial internacional. La no comparecencia supone el control de la competencia por parte del Tribunal. La comparecencia del demandado sitúa en su persona la carga de impugnar la competencia: si no lo hace en forma y momento oportuno, precluye esta posibilidad, deviniendo el Tribunal automáticamente competente (no es necesaria manifestación alguna del demandado admitiendo la competencia: basta con que no la rechace). Por ello es suficiente para entender que el Tribunal ante el que se presentó la primera demanda se ha declarado competente a efectos del art. 19.3 R. 2201 ("Cuando se establezca que es competente el primer órgano jurisdiccional...") y del art. 27 R. 44 ("Cuando el tribunal ante el que se interpuso la primera demanda se declarare competente...") con que este Tribunal no haya declinado de oficio su competencia y ninguna de las partes haya impugnado tal competencia con anterioridad o en el momento de la actuación procesal que el Derecho procesal nacional considere como el primer medio de defensa ${ }^{35}$. Recuérdese, no obstante, que en materia de crisis matrimoniales no está contemplada la sumisión tácita y que los únicos foros operativos son los foros objetivos relacionados en los arts. 3 a 5 R. $2201^{36}$. Ello supone, respecto de la demanda de separación interpuesta por el marido ante los Tribunales italianos, que la

\footnotetext{
${ }^{35}$ Véase ap. 44 de la STJUE de 27 de febrero de 2014, As. C-1/13, Cartier; ap. 16 de la STJUE 24 de junio de 1981, As. C-150/80, Elefanten; ap. 37 de la STJUE de 13 de junio de 2013, As. C-144/12, Goldbet. Se evita de este modo prolongar la duración de la suspensión del pronunciamiento del segundo de los Tribunales, dada la imposibilidad de impugnar ya la competencia del juez ante el que se presentó la primera demanda (ap. 38 y 39 de la STJUE de 27 de febrero de 2014, As. C-1/13, Cartier), y reducir el riesgo de procedimientos paralelos, más grande si se exige al primer Tribunal una declaración expresa o implícita de su competencia (ap. 40 y 41 de la STJUE de 27 de febrero de 2014, As. C-1/13, Cartier).

${ }^{36}$ PalAo MoReno, G., "Crisis matrimoniales internacionales y autonomía de la voluntad", Cursos de Derecho internacional y Relaciones internacionales de Vitoria-Gasteiz 2013, Aranzadi, Cizur Menor, 2014, pp. 451-531, espec. pp. 469-470. Véase, asimismo, BorRÁs Rodríguez, A., "Informe...", loc. cit., Considerando núm. 31. También, Campuzano Díaz, B., "Uniform conflicts of law rules on divorce and legal separation via enhanced cooperation", en CAMPUZANo DíAZ, B./CZEPELAK, M./RodríGuez BenOt, A./RodríGuez VÁzQUEZ, A. (eds.), Latest developments in EU Private International Law, Intersentia, Cambridge-Antwerp-Portland, 2011, pp. 23-48, espec. p. 29; HoDson, D., A practical guide to International Family Law, Bristol, Family Law, 2008, p. 213; Mosconi, F., "Giurisdizione e riconoscimento delle decisioni in materia matrimoniale secondo il Regolamento comunitario del 29 maggio 2000", Rivista di diritto processuale, núm. 2, 2001, pp. 376-408, espec. p. 387. No obstante, Haussmann, R., "Art. 4", en Corneloup, S. (dir.), Droit..., op. cit., p. 246.
} 
comparecencia de la Sra. Grigorescu sin impugnar la competencia no deriva necesariamente en la competencia de los Tribunales de Teramo: en esta materia, la autoridad ante la que se presenta la demanda debe verificar de oficio y en todo caso su competencia (art. 17 R. 2201), con independencia de la voluntad de las partes, aclarando la resolución que resuelve esta verificación (absteniéndose de conocer, de no ser competente; o resolviendo su competencia, como es el caso, de verificar algún criterio que le atribuya competencia) el establecimiento de la competencia de la que habla el art. 19.3 R. 2201 en lo que a la litispendencia se refiere ${ }^{37}$.

Visto lo visto, los órganos jurisdiccionales rumanos deberían haberse inhibido a favor de los órganos jurisdiccionales italianos una vez constatada la declaración de competencia de éstos últimos tanto para causa matrimonial como para la responsabilidad parental ${ }^{38}$. Y todo ello, sin que ni la suspensión del proceso segundo ni su inhibición se condicionen a un juicio de reconoscibilidad de la sentencia futura emitida por el primero de los Tribunales, a una posible excesiva duración del primero de los procesos o a un eventual control de la competencia judicial internacional de los Tribunales italianos ${ }^{39}$, aspecto éste último que no se cuestiona.

\subsection{2.- La competencia del primer Tribunal}

La competencia de los Tribunales italianos para el caso de responsabilidad parental, en aplicación del Reglamento 2201/2003 respecto de un menor con residencia habitual en un Estado UE (Rumanía), se deduce de lo dispuesto en el art. 12.1 R. 2201: este precepto permite a los órganos jurisdiccionales del Estado miembro competentes para la crisis matrimonial (Tribunales italianos respecto de la separación, en este caso) conocer, asimismo, de las "...cuestiones relativas a la responsabilidad parental vinculadas a dicha demanda...", y siempre que "...al menos uno de los cónyuges ejerza la responsabilidad parental sobre el menor...", lo

\footnotetext{
${ }^{37}$ Sobre ello, CANo BAzAGA, E., "El Derecho...", loc. cit., par. B.1.

${ }^{38}$ En este sentido, ap. 60 de las Conclusiones del Abogado General.

${ }^{39}$ No existe una mejor posición del Tribunal ante el que se interpuso la segunda demanda para pronunciarse sobre la competencia del aquél ante el que se interpuso la primera. Por ello, y en atención al principio de confianza comunitario, tanto el art. 27.2 R. 44 (actual art. 29 R. 1215), como el art. 19 R. 2201, hablan de una declaración de competencia y no de control de la competencia del Tribunal ante el que se interpone la primera demanda. En la práctica, STJUE de 9 de diciembre de 2003, As. C-116/02, Gasser. A esta regla le siguen algunas excepciones, como sucede en el ámbito del Reglamento 1215/2012 en materia de competencias exclusivas, cuya especial naturaleza y la exigencia de un control de competencia del juez de origen en sede de reconocimiento, justificaría proceder a un control de la competencia del primero de los Tribunales como condición de aplicación de la excepción de litispendencia (ap. 20 de la STJCE de 27 de junio de 1991, As. C-351/89, Overseas; o STJUE de 27 de febrero de 2014, As. C-1/13, Cartier; así, Fernández RozAS, J.C./SÁnCHEZ LOREnZO, S., Derecho..., op. cit., 2018, p. 102; con dudas, Hess, B./Pfeiffer, T./Schlosser, P., The Brussels I Regulation 44/2001, 2008, p. 102); o que el art. 31.2 R. 1215 hace prevalecer el conocimiento del segundo de los Tribunales elegido expresamente por las partes frente al primero (en el Reglamento 44/2001 no era así, primando el principio de confianza comunitario frente al principio de seguridad jurídica, como se refleja en STJUE de 9 de diciembre de 2003, As. C-116/02, Gasser).
} 
que aquí sucede, así como que "...la competencia de dichos órganos jurisdiccionales haya sido aceptada expresamente o de cualquier otra forma inequívoca por los cónyuges (...) y responda al interés superior del menor...", aspecto cuyo cumplimiento aquí también se entiende en tanto "...haberse personado la Sra. Grigorescu en el litigio (...) haber aceptado (...) por tanto la competencia de dicho órgano jurisdiccional..." (FD 37) ${ }^{40}$.

Tampoco se cuestiona la competencia del Tribunal italiano sobre la demanda reconvencional relativa a los alimentos del hijo común interpuesta por la esposa, regulada, dado que la reclamación se interpone en el año 2007 y que el Reglamento 4/2009 se aplica a aquellas acciones interpuestas después del 18 de junio de 2011, por el Reglamento 44/2001. Por una parte, porque el foro general del domicilio del demandado del art. 2 R. 44 atribuye competencia a los Tribunales de Teramo en tanto que el deudor de alimentos, el Sr. Liberato, se halla domicilio en este Estado. Por otra, porque así se deduce asimismo de la lectura del art. 5.2 R. 44 cuando, "...si se tratare de una demanda incidental a una acción relativa al estado de las personas...", permite conocer de los alimentos del menor al "...Tribunal competente según la ley del foro para conocer de ésta...", como es el caso, y, en evicción de foros exorbitantes, "...salvo que tal competencia se fundamentare exclusivamente en la nacionalidad de una de las partes..."41, lo que aquí no sucede (FD 37). Del mismo modo y de ser el caso, la aplicación del Reglamento 4/2009 permitiría, asimismo, atribuir competencia a los Tribunales italianos en tanto que "...órgano jurisdiccional del lugar donde el demandado tenga su residencia habitual...", u "...órgano jurisdiccional competente en virtud de la ley del foro para conocer de una acción relativa al estado de las personas, cuando la demanda relativa a una obligación de alimentos sea accesoria de esta acción..." (art. 3 R. 4/2009) 42 .

Y esta competencia del Tribunal italiano para conocer de la materia relativa a la crisis matrimonial tampoco se pone en duda. El Reglamento 2201, en vigor en Italia desde el 01 de marzo de 2005 y aplicable a la demanda interpuesta en el año 2007, determina la competencia de los Tribunales italianos a partir de las reglas de este instrumento comunitario en tanto que el cónyuge requerido es nacional comunitario (rumana) con residencia habitual en un Estado UE, en el caso, con base en el criterio del último lugar de residencia habitual de los cónyuges, siempre que uno de

\footnotetext{
${ }^{40}$ Véase ap. 60 de las Conclusiones del Abogado General. Sobre este tipo de competencia, QUIÑONES ESCÁMEZ, A., "Nuevas normas comunitarias en materia de responsabilidad parental (Reglamento (CE) no 2201/2003 del Consejo, de 27.11.2003)", Indret, núm. 4, 2004, par. 3.3.a; o CARO GÁNDARA, R., "Nuevos desafíos comunitarios en materia matrimonial y de responsabilidad parental en las relaciones jurídicas transfronterizas (competencia judicial internacional, reconocimiento y ejecución de resoluciones en materia de familia y sustracción internacional de menores a la luz del Reglamento 2201/2003)", Estudios Jurídicos, 2004, pp. 4695-4731, espec. pp. 47104714.

${ }^{41}$ Álvarez GonzÁLEZ, S., Crisis matrimoniales internacionales y prestaciones alimenticias entre cónyuges, Madrid, 1996, pp. 77-82.

42Álvarez González, S., "El Reglamento 4/2009/CE...", loc. cit., par. V.1.
} 
ellos aún resida allí, o por la residencia habitual del demandante en Italia siendo asimismo nacional italiano (art. 3 R.2201) ${ }^{43}$. Recuérdese el "...carácter exclusivo de las competencias definidas en los artículos 3, 4 y 5...", al establecer el art. 6 R. 2201 que "...un cónyuge que: (...) tenga su residencia habitual en el territorio de un Estado miembro, o bien (...) sea nacional de un Estado miembro (...) sólo podrá ser requerido ante los órganos jurisdiccionales de otro Estado miembro en virtud de los artículos 3,4 y $5 . . . "$, como es el caso, no siendo operativo el sistema doméstico (italiano, en el caso), que únicamente actuaría respecto de residentes en terceros Estados y no nacionales de un Estado UE y siempre que "...de los arts. 3, 4 y 5 (del R. 2201) no se deduce la competencia de ningún órgano jurisdiccional de un Estado miembro..." (foro de competencia residual del art. 7 R. 2201) ${ }^{44}$.

\subsection{3.- El error del segundo Tribunal}

Así las cosas, la Curtea de Apel București debió operar de acuerdo con las exigencias del art. 19 R. 2201 (y art. 27 R. 44) en relación con el supuesto de litispendencia que se le había planteado tanto para la decisión relativa a la disolución matrimonial como para sus consecuencias en lo que respecta al menor, además de la reclamación relativa a las obligaciones alimenticias. Recuérdese que el comportamiento del segundo de los Tribunales en casos de litispendencia no es opcional sino obligatorio: el carácter imperativo de las reglas de litispendencia previstas en los arts. 19 R. 2201 y art. 27 R. 44 (a diferencia de las reglas de conexidad del art. 28 R. 44, por ejemplo, de naturaleza diferente, ausentes en el Reglamento 2201/2003) tiene que ver con la evicción de "...procesos paralelos ante los órganos jurisdiccionales de diferentes Estados miembros y los conflictos entre resoluciones judiciales que pudieran resultar de ellos..."45, contribuyendo de este modo a la aplicación del principio del reconocimiento de pleno derecho de las resoluciones judiciales dictadas en los Estados miembros, fundamentado en el principio de confianza mutua.

No haciéndolo, como se demuestra por la emisión de su Sentencia de 12 de junio de 2013, la Curtea de Apel București no sólo aplica de manera incorrecta el Derecho comunitario cuando desestima la excepción de litispendencia formulada por el Sr. Liberato, basada en las demandas relativas al vínculo matrimonial (FD 35 y 38), también emplea argumentos erróneos para justificar su respuesta. Por un lado, por fundamentar su comportamiento en la normativa nacional rumana reguladora de la litispendencia y de la autoridad de cosa juzgada y no en la normativa comunitaria al efecto, de interpretación autónoma, como apuntamos. Por

\footnotetext{
${ }^{43}$ Sobre los posibles foros, CARo GÁnDARA, R., "Nuevos...", loc. cit., pp. 4707-4708.

${ }^{44}$ Véase la STJCE de 29 de noviembre de 2007, As. C-68/07, Sundelind v. López. Al respecto, REQUEJO IsIDRO, M., "Regulation (EC) 2201/03 and its personal scope. ECJ, November 29, 2007 Case C-68/07, Sundelind López", Yearbook of Private International Law, 2008, pp. 579-591; o SÁNCHEZ JiMÉNEZ, M.A., El divorcio...., op. cit., p. 38.

${ }^{45}$ Véase ap. 29 de la STJUE de 6 de octubre de 2015, As. C-489/14, A.; ap. 64 de la STJUE de 9 de noviembre de 2010, As. C-296/10, Purrucker; o ap. 40 de la STJUE de 27 de febrero de 2014, As. C-1/13, Cartier.
} 
otro, y aun cuando ya vimos como las acciones dependientes tiene la misma respuesta en materia de crisis matrimoniales que la litispendencia más ortodoxa, por excluir la aplicación del art. 19 R. 2201 con base en la disparidad de objeto, tal como considera cuando dice que "...del tenor del art. 19 R. 2201 (...) se desprende inequívocamente que las dos demandas concurrentes deben tener en común únicamente uno de los tres objetos y no dos objetos distintos entre aquellos expresa y limitativamente enumerados por el texto. [...] En el presente asunto, cada una de las demandas tiene un objeto distinto, a saber, la separación en Italia y el divorcio en Rumanía, lo que excluye la aplicación del art. 19 R. 2201...". Y, finalmente, por apelar al desconocimiento en la legislación rumana de la institución de la separación, al entender que ".... el órgano jurisdiccional de apelación consideró acertadamente que el sistema rumano ignora la institución de la separación. En consecuencia, es evidente que no puede haber identidad con tal demanda presentada ante los órganos jurisdiccionales de otro Estado miembro. Aun cuando dicha institución sea conocida, es preciso señalar que no existe identidad entre divorcio y separación...": el segundo de los Tribunales debe inhibirse a favor de aquél ante el que se interpuso la primera de las demandas aun cuando en el Derecho doméstico de ese Estado miembro no se conozca la separación (o la nulidad) 46 .

En cualquier caso, la actuación del Tribunal rumano debe medirse en los términos expuestos y no a partir de la jurisprudencia del TJUE derivada de la STJUE de 22 de diciembre de 2010, Mercredi ${ }^{47}$, que entiende que, en caso de litispendencia, una resolución en materia de responsabilidad parental dictada por un órgano jurisdiccional ante el que se hubiere presentado la segunda demanda, incumpliendo la obligación de suspender el procedimiento, no "...afectarí(a)..." a la resolución que debe dictar el órgano jurisdiccional ante el que se interpuso la demanda en primer lugar. Al igual que considera el Abogado General y a diferencia de lo que defiende la Comisión Europea, no parece extrapolable esta resolución al litigio que ahora nos ocupa, en tanto que, de acuerdo con lo determinado por el TJUE, la sentencia controvertida dictada por el órgano jurisdiccional ante el que se interpuso la demanda en segundo lugar aún no había adquirido firmeza, lo que, unido a las dudas relativas a la residencia del hijo menor y la interrelación del procedimiento para su restitución, justifica la respuesta concreta ofrecida en este caso ${ }^{48}$.

\footnotetext{
${ }^{46}$ Así, Borrás Rodríguez, A.,"Informe...", loc. cit., p. 47; Cano Bazaga, E., "El Derecho...", loc. cit., par. B.2.

${ }^{47}$ Véanse ap. 68 y 69 de la STJUE de 22 de diciembre de 2010, As. C-497/10, Mercredi. ${ }^{48}$ Véase ap. 67 de las Conclusiones del Abogado General; y ap. 67 y 70 de la STJUE de 22 de diciembre de 2010, As. C-497/10, Mercredi.
} 


\section{3.- RECONOCIMIENTO DE UNA RESOLUCIÓN EXTRANJERA E INFRACCIÓN DE LAS REGLAS DE LITISPENDENCIA: INTERACCIÓN 3.1.- La infracción de las reglas de litispendencia no es causa de denegación de reconocimiento}

A nuestro entender y de acuerdo con el TJUE (FD 56), una eventual infracción de las reglas de litispendencia por parte del Tribunal de origen que dictó aquella resolución que pretende ahora reconocerse en otro Estado miembro no constituye causa de denegación de reconocimiento. Esta circunstancia no encaja en ninguna de las condiciones posibles cuya quiebra permite denegar la homologación de la sentencia extranjera, tal como parece deducirse de una lectura básica de los motivos de denegación del reconocimiento de resoluciones en materia de divorcio, separación judicial o nulidad matrimonial del art. 22 R. 2201, de la relación de motivos expuestos en materia de responsabilidad parental del art. 23 R. 2201, así como de aquéllos determinados por los arts. 34 y 35 R. 44 en lo que a las obligaciones alimenticias se refiere.

El no encaje de la quiebra de las reglas de litispendencia resulta concluyente en un amplio grupo de motivos de denegación. No se ajusta al supuesto de hecho relativo a la inconciliabilidad con otra resolución ya existente en el Estado requerido o con otra resolución anterior en otro Estado susceptible de ser reconocida en el Estado requerido (arts. 22.c y d R. 2201; art. 23.d y f R. 2201; art. 34.3 y 4 R. 44). Tampoco tiene sentido cuestionarse su ubicación en aquellos motivos que hablan de un menoscabo del ejercicio de la responsabilidad parental por haberse dictado la resolución sin haber dado posibilidad de audiencia al perjudicado o haberlo hecho sin respeto al procedimiento previsto en el art. 56 R.2201 (art. 23.d y g R. 2201). No tiene amparo, tampoco, en aquellas normas que imponen al Tribunal del Estado requerido un ejercicio de no-hacer y que funcionan, más que como condiciones, como presupuestos a la hora de enfrentarse al reconocimiento de una resolución extranjera, tales como la imposibilidad de someter a la resolución extrajera a una revisión en cuanto al fondo (art. 26 R. 2201; art. 36 R. 44) o de condicionarla a eventuales diferencias de Derecho aplicable en lo que a divorcio, separación judicial o nulidad matrimonial se refiere.

Resulta necesario examinar, no obstante, dos condiciones denegatorias del reconocimiento cuyo supuesto de hecho podría acoger, al menos a priori, la infracción de las reglas de litispendencia por parte del Tribunal de origen: primero, y dada la incidencia de la normativa reguladora de la litispendencia en la determinación de la competencia judicial internacional, la condición de reconocimiento referida al control de la competencia del órgano jurisdiccional de origen; $y$, segundo, la condición genérica de no contradicción con el orden público internacional del Estado requerido 49 .

$Y$ es que, por lo que se refiere al control de la competencia del juez de origen y tal como plantea el TJUE, de constituir las reglas reguladoras de la litispendencia verdaderas normas de competencia judicial internacional "...del mismo modo que las que figuran en los arts. 3 a 14 de este

\footnotetext{
${ }^{49}$ Del mismo modo, Álvarez González, S., "Litispendencia...", loc. cit., par. 5.
} 
Reglamento (2201/2003)..." (FD 49), su eventual infracción no impediría el reconocimiento de la resolución extranjera. Por un lado, dada la prohibición del control de la competencia del Tribunal de origen que el art. 24 R. 2201 establece tanto en crisis matrimoniales como en responsabilidad parental, de la misma manera que hace el art. 35.2 R. 44 en lo que a los alimentos se refiere, si bien verificable en supuestos excepcionales, como son las materias de consumo, seguros 0 competencias exclusivas (art. 35.1 R. 44), que no es el caso (FD 45) ${ }^{50}$. Y, por otro, porque esta circunstancia tampoco encaja en la condición denegatoria de violación del orden público internacional, en tanto que el legislador europeo, precisamente para evitar la conversión de esta condición en cajón de sastre, se encarga específicamente de determinar, respecto de las crisis matrimoniales y responsabilidad parental, que "...el criterio de orden público a que se refieren la letra a) del art. 22 y la letra a) del art. 23 no podrá aplicarse a las normas de competencia establecidas en los arts. 3 a 14 (R. 2201)..." (art. 24 R. 2201), haciendo lo propio, esta vez en materia de obligaciones de alimentos, cuando estima que "...el orden público contemplado en el punto 1 del art. 34 (R. 44) no afectará a las reglas relativas a la competencia judicial..." (art. 35.3 R. $44)^{51}$.

En línea con lo expuesto, la no consideración de las reglas reguladoras de la litispendencia como verdaderas normas de competencia judicial internacional (e incluso, si bien con mayores dificultades, también en el caso de su equivalencia ${ }^{52}$ ) exige valorar, asimismo y al margen de esta vinculación entre orden público y competencia que acabamos de exponer, si la infracción de las reglas de litispendencia puede constituir una violación de la condición genérica de no contradicción con el orden público internacional del Estado requerido. Se trataría de verificar si el no respeto a las reglas de litispendencia por parte del Tribunal que dictó sentencia y no debió hacerlo conforma una infracción manifiesta de una norma jurídica considerada esencial en el ordenamiento jurídico de la Unión y, por tanto, en el del Estado miembro requerido, o de un derecho reconocido como fundamental en esos ordenamientos jurídicos; 0 , tal como considera la Corte di cassazione italiana como órgano remitente, una quiebra al orden público procesal en tanto que menoscabo de la función y finalidad de normas imperativas basadas en la confianza y

\footnotetext{
${ }^{50}$ Véase ap. 85 de la STJUE de 9 de noviembre de 2010, As. C-296/10, Purrucker. En la doctrina, MAGNus, U./MANKowSKI, P. (ed.), European..., op. cit., p. 286.

${ }^{51}$ En relación con el art. 24 R. 2201, GAUDEMET-TALLON, $H_{\text {., }}$ "Le Règlement no 1347/2000...", loc. cit., p. 408; ANCEL, B./MUir WATT, H., "La désunion...", loc. cit., p. 444; también, ChalAS, C., "Art. 24 R 2201", en Corneloup, S. (dir.), Droit..., op. cit., pp. 402403, incluyendo en esta prohibición de ubicar en el orden público las reglas de competencia del Reglamento 2201/2003 así como las competencias residuales del art. 7 R. 2201. En relación con el art. 35.3 R. 44, Virgós Soriano, M./Garcimartín AlFérez, F.J., Derecho procesal..., op. cit., p. 613; JenARD, P., "Informe sobre el Convenio de 27 de septiembre de 1968 relativo a la competencia judicial y a la ejecución de resoluciones judiciales en materia civil y mercantil" (Informe JeNARD), DOCE C 189, 28 de julio de 1990, p. 44; Gaudemet-Tallon, H., Compétence..., op. cit., p. 506.

52También lo plantea Álvarez GonzÁlez, S., "Litispendencia...", loc. cit., par. 5 y 6.
} 
lealtad procesal recíproca entre los Estados miembros como fundamento del reconocimiento recíproco de resoluciones judiciales.

Como adelantábamos, el examen conjunto que el TJUE hace a la doble pregunta formulada en la cuestión prejudicial del órgano italiano remitente en los términos expuestos (FD 32) concluye en una respuesta negativa, al menos, en lo que se refiere a los límites del supuesto que da lugar a la intervención del Tribunal de Justicia (FD 56) ${ }^{53}$. No podemos decir que no estemos de acuerdo, si bien es cierto, asimismo, que no debe descartarse la existencia de ciertos casos, en los que no entró el TJUE en la resolución comentada, en los que una eventual infracción de las reglas de litispendencia sí pueda dar lugar a una vulneración del orden público internacional del Estado requerido.

\section{2.- Vinculación entre las reglas de litispendencia y las normas de competencia judicial internacional.}

Las reglas reguladoras de las situaciones de litispendencia no son equivalentes a las normas de competencia judicial internacional. Habida cuenta de que la jurisdicción de los Tribunales y autoridades estatales no se proyecta sobre la totalidad de las situaciones privadas internacionales, las normas de competencia judicial internacional se encargan de determinar y delimitar aquellas situaciones de tráfico privado externo respecto de las cuales los órganos jurisdiccionales y autoridades de cada Estado pueden conocer ${ }^{54}$. Las reglas de litispendencia tienen otra función, vinculada a aquella serie de problemas que plantea la puesta en práctica de las normas de competencia judicial internacional y a los que el legislador europeo, convencional y autónomo procura dar respuesta a partir de otro tipo de normas. Es lo que sucede con la determinación de la naturaleza de oficio o a instancia de parte de la verificación de la competencia judicial internacional, los efectos del factor tiempo o la derogatio fori en su determinación, o, en lo que ahora interesa, las reglas que regulan la admisibilidad e identificación de los criterios operativos de las situaciones de litispendencia internacional. En consecuencia, las reglas reguladoras de la litispendencia no tienen por objetivo delimitar aquellas situaciones de tráfico privado externo respecto de las cuales los Tribunales y autoridades de cada Estado pueden conocer, lo que corresponde a las normas de competencia judicial internacional, sino que parten de las determinación de la competencia del órgano jurisdiccional que se trate, ocupándose, por el contrario, de guiar al operador jurídico que se encuentra ante una pluralidad de procesos formal o sustancialmente idénticos: las normas de competencia judicial internacional responden de esta manera a los caracteres de las normas de regulación y las reglas de litispendencia a aquéllos propios de las normas de aplicación ${ }^{55}$. O, lo que

\footnotetext{
${ }^{53}$ Véase también, en el mismo sentido, ap. 82 de las Conclusiones del Abogado General.

${ }^{54}$ Sobre ello, FERnÁndez RozAs, J.C./SÁnCHEZ Lorenzo, S., Derecho..., op. cit., 2018, p. 53.

${ }^{55} \mathrm{Al}$ respecto, GARDEÑES SANTIAGO, M., "Litispendencia y cosa juzgada en el extranjero ante la nueva LEC", AEDIPr., 2001, pp. 315-337, espec. 325-326; GARDEÑES SANTIAGO, M., "Procedimientos paralelos en España y en el extranjero: el Título IV de la Ley 29/2017 (arts. 37 a 40)", REDI, vol. LXVIII, 2016-I, pp. 109-119, espec. p. 117; FERnÁndez RozAs, J.C./SÁnCHEZ LoRENZO, S., Derecho..., op. cit., 2018, p. 60.
} 
es lo mismo, de entender que el control de competencia del juez de origen tiene como objetivo impedir el reconocimiento de una resolución dictada por una autoridad objetivamente alejada de las circunstancias del caso, vulnerando, en consecuencia, los derechos procesales de las partes, podemos convenir que no es lo mismo rechazar el reconocimiento porque quien haya dictado sentencia haya sido el segundo de los Tribunales, esto es, por una cuestión de prioridad temporal, a hacerlo porque el órganos jurisdiccional extranjero conoció con base en foros no objetivos 0 exorbitantes ${ }^{56}$.

Con todo, y a pesar de esta ausencia de equivalencia, no puede decirse que entre las reglas de litispendencia y las normas de competencia judicial internacional no haya una relación estrecha.

Primero, porque, aunque es cierto que las normas de competencia judicial internacional relacionadas en el art. 19 R. 2201 no figuran entre las reglas de competencia a las que expresamente se refiere el art. 24 R. 2201 (secciones 1 y 2), el art. 19 R. 2201 regulador de la litispendencia sí forma parte del capítulo II del Reglamento 2201/2003 (sección 3: disposiciones comunes), que lleva por título aquél de "...Competencia..." (FD 50 y 53$)^{57}$.

Segundo, porque, de alguna manera, en las relaciones que se establecen entre los órganos jurisdiccionales participantes de la situación original de litispendencia y posterior de reconocimiento, se realiza un efectivo control de la competencia del segundo de los Tribunales implicados. Es lo que sucede en el caso que nos ocupa. A la hora de pronunciarse sobre una demanda incidental de reconocimiento, el órgano jurisdiccional ante el que se presentó la primera demanda (el Tribunal italiano de Teramo) procede a comprobar si las normas de litispendencia han sido aplicadas correctamente por el órgano jurisdiccional ante el que se interpuso la segunda demanda (el Tribunal rumano), esto es, aprecia las razones por las que el segundo de los Tribunales no ha declinado su competencia. En consecuencia, el órgano jurisdiccional ante el que se interpuso la primera demanda procede así necesariamente al control de la competencia del órgano jurisdiccional ante el que se interpuso la segunda (FD 51 y 53$)^{58}$.

Tercero, porque no extraña esta ampliación de las normas afectadas por una disposición del Reglamento 2201/2003 en tanto que el TJUE extendió en otra práctica la prohibición de la aplicación del criterio basado en la

\footnotetext{
${ }^{56}$ Del mismo modo, Álvarez González, S., "Litispendencia...", loc. cit., par. 7. Piénsese, además, en sistemas como la Ley 29/2015, de 30 de julio, de cooperación jurídica internacional en materia civil, que recogen el control de competencia del juez de origen en una condición específica (en el caso, art. 46.1.c LCJI) y el control de la litispendencia en otra diferente (en el caso, art. 46.1.f LCJI: "(I)as resoluciones judiciales extranjeras firmes no se reconocerán... (c)uando existiera un litigio pendiente en España entre las mismas partes y con el mismo objeto, iniciado con anterioridad al proceso en el extranjero..."), lo que es muestra de la naturaleza y finalidades diferentes de las reglas de competencia y aquéllas de litispendencia.

${ }^{57}$ Véase ap. 76 de las Conclusiones del Abogado General.

${ }^{58}$ Véase ap. 77 de las Conclusiones del Abogado General. También, por analogía, en lo que se refiere al art. 15 R. 2201, ap. 45 de la STJUE de 19 de noviembre de 2015, As. C$455 / 15, P$.
} 
contrariedad con el orden público del Estado miembro requerido, esta vez, para incluir el art. 15 R. 2201: "...una supuesta infracción del art. 15 de dicho Reglamento por el órgano jurisdiccional de un Estado miembro no permite al órgano jurisdiccional de otro Estado miembro controlar, a pesar de que la prohibición establecida en el art. 24 del mismo Reglamento no contiene ninguna referencia expresa a dicho art. 15, la competencia de ese primer órgano jurisdiccional..."59.

Cuarto, porque parece difícil de justificar que la vulneración de las reglas que resuelven un problema de convivencia de procesos en caso de procedimientos paralelos ${ }^{60}$ reciba un trato más estricto que la falta de verificación de la competencia o los errores que se cometan a tal respecto, ajenos a cualquier control ex art. 24 R. 220161. En tal sentido, téngase en cuenta que "...el juez del Estado requerido no puede, sin poner en peligro la finalidad del Reglamento n. 2201/2003, denegar el reconocimiento de una resolución emanada de otro Estado miembro por el mero hecho de que considere que, en esa resolución, se ha aplicado mal el Derecho nacional o el Derecho de la Unión..." (FD 54)62.

Así pues, y desde esta óptica, las normas de competencia judicial internacional y aquéllas reguladoras de las situaciones de litispendencia son equiparables. En consecuencia, y aun cuando la prohibición establecida en el art. 24 R. 2201 no contiene una referencia expresa al art. 19 R. 2201, el órgano jurisdiccional ante el que se interpuso la primera demanda no puede denegar el reconocimiento de una resolución emitida por el órgano jurisdiccional ante el que se interpuso la segunda de las demandas en violación de la norma de litispendencia recogida en el art. 19 R. 2201 en la medida en que ello implica controlar la competencia del órgano jurisdiccional ante el que se interpuso la segunda reclamación ${ }^{63}$.

\footnotetext{
${ }^{59}$ Véase ap. 45 de la STJUE de 19 de noviembre de 2015, As. C-455/15, $P$.

${ }^{60}$ En la STJUE de 16 de julio de 2009, As. C-168/08, Hadadi, se emplea el término conflicto de competencia a la hora de describir aquel supuesto en el que se inicien procedimientos ante los Tribunales de varios Estados miembros de conformidad con el art. 3 R. 2201 y al que debe aplicársele el art. 19 R. 2201 regulador de las situaciones de litispendencia en materia de crisis matrimoniales. Lo mismo en ap. 37 de la STJUE de 9 de octubre de 2014, As. C-376/14, C.

${ }^{61}$ Véase ap. 79 de las Conclusiones del Abogado General.

${ }^{62}$ En estos términos, ap. 49 de la STJUE de 16 de julio de 2015, As. C-681/13, Diageo Brands; o ap. 46 de la STJUE de 19 de noviembre de 2015, As. C-455/15, P.

${ }^{63}$ Véase ap. 80 de las Conclusiones del Abogado General, así como ap. 52 de la resolución que comentamos. El Abogado General, dada la importancia de esta cuestión, sugiere que se añada una propuesta relativa al referido art. 24 R. 2201 aprovechando la refundición del Reglamento 2201/2003. No consta por ahora la presentación de ninguna modificación relativa a las normas de competencia en el proyecto inicial, a saber, ni en la Propuesta de Reglamento del Consejo relativo a la competencia, el reconocimiento y la ejecución de resoluciones en materia matrimonial y de responsabilidad parental, y sobre la sustracción internacional de menores (refundición) (COM (2016) 411 Final), ni en la resolución legislativa del Parlamento Europeo de 18 de enero de 2018 sobre esta Propuesta (http://www.europarl.europa.eu/sides/getDoc.do?pubRef=//EP//TEXT+TA+P8-TA-2018-0017+0+DOC+XML+V0//ES). Por el contrario, no parece incluir el art. 19 R. 2201 regulador de la litispendencia en esta prohibición de control de
} 
A este control de competencia se opone, en lo que a crisis matrimoniales y responsabilidad parental se refiere y como vimos, el art. 24 R. 2201 (FD 51 ), extendiendo el TJUE estas consideraciones de no control también a aquellas normas de litispendencia que figuran en el art. 27 R. 44 en materia de obligaciones alimentarias (FD 53) en tanto que el art. 35.3 R. 44 prohíbe asimismo proceder a la comprobación de la competencia de los órganos jurisdiccionales del Estado miembro de origen ${ }^{64}$.

\section{3.- El orden público internacional y la quiebra de las reglas de litispendencia por parte del juez de origen}

\subsection{1.- En su proyección desde la competencia judicial internacional}

Como acabamos de ver, la estrecha relación existente entre las reglas de litispendencia y las normas de competencia judicial internacional permite situar la cuestión del no respeto a las normas de litispendencia en sede de reconocimiento, y aun cuando la ausencia de equivalencia entre ambas instituciones, en el ámbito de la prohibición directa del control de competencia del juez de origen que establece el legislador europeo en los arts. 24 R. 2201 y 35.3 R. 44. Del mismo modo, la equiparación a estos efectos entre reglas de litispendencia y aquéllas de competencia judicial internacional tiene como consecuencia su también ubicación en la prohibición indirecta de control de la competencia del juez de origen que establece el legislador europeo en su labor de delimitación de los contornos del genérico orden público como condición denegatoria de reconocimiento. Como vimos, "...el criterio de orden público a que se refieren la letra a) del art. 22 y la letra a) del art. 23 no podrá aplicarse a las normas de competencia establecidas en los arts. 3 a 14 (R. 2201)...", y "...el orden público contemplado en el punto 1 del art. 34 (R. 44) no afectará a las reglas relativas a la competencia judicial...".

Estamos de acuerdo. Piénsese que, en tanto que, en el espacio judicial europeo, opera como pilar básico la libre circulación de resoluciones, lo que es coherente con el principio de reconocimiento mutuo y de confianza entre las autoridades de los Estados miembros (FD 41) ${ }^{65}$, las condiciones denegatorias de reconocimiento de resoluciones deben interpretarse de manera restrictiva, reforzando de esta manera su naturaleza tasada y exhaustiva ${ }^{66}$. En consecuencia, la operatividad de la condición denegatoria

competencia del juez de origen del art. 24 R. 2201, Ni ShúlleABÁHIN, M., Cross-Border..,, op. cit., p. 258, nota núm. 176.

${ }^{64}$ Procediendo, asimismo, a esta extensión a la materia de alimentos, ap. 81 de las Conclusiones del Abogado General.

${ }^{65}$ Véase el ap. 41 de la resolución comentada, cuando estima que "...este Reglamento se fundamenta en la cooperación y en la confianza mutua entre los órganos jurisdiccionales, que deben llevar al reconocimiento mutuo de las resoluciones judiciales, piedra angular de la creación de un auténtico espacio judicial..."; también, ap. 50 de la STJUE de 15 de febrero de 2017, As. C-499/15, W y V; ap. 81 de la STJUE de 9 de noviembre de 2010, As. C-296/10, Purrucker; o ap. 70 de la STJUE de 15 de julio de 2010, As. C-256/09, Purrucker. En la doctrina, Gaudemet-Tallon, H., "Le Règlement no 1347/2000...", loc. cit., p. 410.

${ }^{66}$ Afirmando el carácter restrictivo de la interpretación de las condiciones de los art. 34 y 35 R. 44, ap. 55 de la STJUE de 28 de abril de 2009, Apostolides; ap. 33 de la STJUE de 
del exequatur basada en el orden público internacional de los arts. 22.a y 23.a R. 2201 y art. 34 R. 44 debe tener igualmente carácter excepcional, restrictivo y proporcionado (FD 55) ${ }^{67}$, en tanto que "...constituyen un obstáculo a la realización de uno de los objetivos fundamentales de dichos Reglamentos..." como es el principio de confianza mutua (FD 46 y 55), lo que no casa con ampliar esta condición, siquiera vía interpretativa, permitiendo un control de competencia del juez de origen prohibido por la regla general del sistema ${ }^{68}$.

Lo expuesto se adecúa a los principios que guían la estructura y funcionamiento de los Reglamentos 44/2001 y 2201/2003 en este ámbito del reconocimiento.

Primero, porque el procedimiento tendente al reconocimiento de una resolución extranjera no constituye un nuevo proceso, de manera que introducir elementos en su desarrollo extraños a los propuestos por el legislador en el Reglamento 2201/2003 y/o Reglamento 44/2001, en el caso, ampliación de los motivos de denegación del exequatur, no encaja con su naturaleza básicamente formal u homologadora alejada del fondo ${ }^{69}$. Recuérdese, al respecto, que el art. 26 R. 2201 prohíbe expresamente cualquier revisión en cuanto al fondo, lo mismo que sucede con el art. 36 R. 44.

13 de octubre de 2011, Prism Investments BV; STJUE de 28 de marzo de 2000, As. C7/1998, Krombach; o STJUE de 2 de junio de 1994, Kleinmotoren. En la doctrina, VIRGós Soriano, M./Garcimartín Alférez, F.J., Derecho procesal..., op. cit., p. 600; KAYE, P., Civil jurisdiction and enforcement of foreign judgements, 1987, p. 1437; SÁNCHEZ JiMÉNEZ, M.A., "Art. 29 CB", en Calvo Caravaca, A.L. (dir.), Comentario al Convenio de Bruselas relativo a la competencia judicial y a la ejecución de resoluciones judiciales en materia civil y mercantil, Madrid, 1994, pp. 506-514, espec. p. 511. Respecto del Reglamento 2201/2003, en el mismo sentido, ap. 36 de la STJUE de 19 de noviembre de 2015, As. C455/15, P.; en la doctrina, Calvo Caravaca, A.L./Carrascosa González, J., Derecho internacional privado, $18^{a}$ ed., vol. I, 2018, p. 301; O GAUDEMET-TALLON, H., "Le Règlement no 1347/2000...", loc. cit., p. 411. Y en comentario a este caso Liberato, Álvarez GonzÁlez, S., "Litispendencia...", loc. cit., par. 1.

${ }^{67}$ Véanse, al respecto, ap. 38 de la STJUE de 25 de mayo de 2016, As. C-559/14, Meroni; ap. 46 de la STJUE de 23 de octubre de 2014, As. C-302/13, Lithuanian Airlines; o ap. 48 de la STJUE de 06 de septiembre de 2012, As. C-619/10, Trade Agency.

${ }^{68}$ Véase ap. 36 de la STJUE de 19 de noviembre de 2015, As. C-455/15, P.

${ }^{69}$ Véase Virgós Soriano, M./Garcimartín AlFérez, F.J., Derecho procesal..., op. cit., p. 636, cuando indican que el Tribunal del Estado requerido no actúa como "...una instancia revisora...", sino como "...una instancia homologadora..." de la resolución extranjera; O'MAlley, S./Layton, A., European..., op. cit., pp. 733-734; también, JenARD, P., "Informe...", loc. cit., p. 163. Afirmando esta naturaleza homologadora del exequátur, por ejemplo, ATS de 8 de septiembre de 1998 (RJ 1998\6840), entendiendo que su objeto es verificar el cumplimiento de los requisitos establecidos en las normas (generalmente de naturaleza procesal), sin que se pueda revisar el fondo del asunto, más allá de lo que imponga el orden público; o, en parecido sentido, ATS de 24 de noviembre de 1998 (RJ 1998\9228); asimismo, AAP de Madrid de 30 de marzo de 2006, o el AAP de Madrid de 17 de abril de 2007 (UR 2007\212010), respecto de la imposibilidad de volver a valorar las apreciaciones de hecho o jurídicas realizadas por el Tribunal de origen; también, el AAP de Cádiz de 07 de marzo de 2002 (JUR 2002\138099), respecto de la imposibilidad de modificación por parte del juez del Estado requerido del fallo dictado por el juez del Estado de origen en un caso de menores. 
Segundo, porque la ampliación de los motivos de denegación del exequatur no encaja tampoco con la tendencia del legislador europeo dirigida a la liberación del régimen de circulación de las resoluciones judiciales extranjeras en sede de espacio judicial europeo ${ }^{70}$. Considerar un motivo de denegación de exequatur ajeno a los relacionados en los arts. 23 y 24 R. 2201, o arts. 34 y 35 R. 44, o ampliar la interpretación de los expresamente determinados por el legislador, casa mal con unos instrumentos que, basados en la confianza recíproca en la justicia y en orden a facilitar que una resolución dictada en un Estado miembro distinto del requerido produzca aquí los mismos efectos que un título nacional de idéntica naturaleza, establecen un sistema de reconocimiento basado en los principios de eficacia, celeridad y uniformidad ${ }^{71}$.

Tercero, porque, coherente con el principio de confianza mutua que fundamenta el reconocimiento y la ejecución de las resoluciones judiciales en el Reglamento 2201/2003 (Considerando núm. 21 R. 2201), "...los motivos de denegación del reconocimiento deben limitarse al mínimo necesario..." (FD 46) $)^{72}$.

El carácter restrictivo con el que deben ser interpretadas las condiciones de reconocimiento y que refuerza asimismo su naturaleza tasada y exhaustiva, puede observarse en distintas situaciones. Por ejemplo, y específicamente relacionada con el orden público, la imposibilidad de proponer una ampliación de la vía del orden público en orden a evitar el reconocimiento de una resolución extranjera dictada con base en una normativa material diferente a la seleccionada por el D.i.pr. del Estado requerido, esto es, un control de ley aplicada ${ }^{73}$. Más casos, ahora respecto

\footnotetext{
${ }^{70}$ Respecto de esta tendencia, en relación con el Reglamento 44/2001 y Reglamento 1215/2012, De Miguel Asensio, P., "Espacio europeo de justicia: evolución y perspectivas en el sector del reconocimiento y ejecución de decisiones", AEDIPr., 2006, pp. 441-466; DuRÁn AYAGO, A., "Europeización del Derecho internacional privado: del Convenio de Bruselas de 1968 al Reglamento (UE) 1215/2012. Notas sobre el proceso de construcción de un espacio judicial europeo", Revista General del Derecho Europeo, vol. 29, 2013, pp. 1-55; SÁNCHEZ LORENZO, S., "Competencia judicial y reconocimiento y ejecución de decisiones en materia civil y mercantil: del Convenio de Bruselas al Reglamento Bruselas I", en Cooperación jurídica internacional en materia civil. El Convenio de Bruselas, BorRás Rodríguez, A. (dir.), Cuadernos de Derecho Judicial, 2001-IV, CGPJ, Madrid, 2001, pp. 181-228, espec. p. 215.

${ }^{71}$ Véase ap. 27 de la STJUE de 13 de octubre de 2011, As. C-139/10, Prism Investments BV v. Jaap Anne van der Meer, cuando entiende que "...el régimen de reconocimiento y ejecución previsto en dicho Reglamento se basa en la confianza recíproca en la justicia dentro de la Unión Europea...", exigiendo tal confianza "...no sólo que las resoluciones judiciales dictadas en un Estado miembro sean reconocidas de pleno Derecho en otro Estado miembro, sino también que sea eficaz y rápido el procedimiento para hacer ejecutorias, en este último Estado, dichas resoluciones...".

${ }^{72}$ Véase ap. 35 de la STJUE de 19 de noviembre de 2015, As. C-455/15, P. También, ap. 50 de la STJUE de 15 de febrero de 2017, As. C-499/15, $W$ y $V$, en la consideración del principio de reconocimiento mutuo de las resoluciones judiciales como "...piedra angular de la creación de un auténtico espacio judicial..."; o, en el mismo sentido, ap. 70 de la STJUE de 15 de julio de 2010, As. C-256/09, Purrucker. En la doctrina, GAUDEMET-TALLON, H., "Le Règlement no 1347/2000...", loc. cit., p. 410.

73Véase Calvo Caravaca, A.L./Carrascosa González, J., Derecho..., op. cit., 2018, p. 301 y p. 437, respecto de la ley aplicable como no integrante del orden público; GAUDEMET-
} 
de la generalidad de las condiciones denegatorias, serían la imposibilidad de alegar la excepción material de cumplimiento de la pretensión por compensación de créditos en la fase de reconocimiento (cuando debería hacerse en la fase de ejecución material), o la (im)posibilidad de utilizar la alegación de prescripción vinculada a la acción causal o del pago de la deuda, o de emplear motivos diferentes a los relacionados en el régimen aplicable ${ }^{74}$. Este carácter restrictivo con el que deben ser interpretadas las condiciones de reconocimiento es lo que se halla detrás de las dificultades que existieron para situar en el art. 34.2 R. 44 (actual art. 45 R. 1215) ciertas garantías procesales ajenas a su tenor: el art. 34.2 R. 44 basa la vulneración de los derechos de defensa como causa de denegación de exequátur en la falta de forma de la notificación de la demanda al demandado que le haya impedido una defensa real en el proceso de origen y la falta de tiempo para preparar una defensa procesal en el proceso de origen, no siendo posible ampliar el alcance de este precepto por vía de interpretación para ubicar en su ámbito de aplicación derechos vinculados a la defensa de la posición del demandado y no expresamente recogidos en su tenor (por ejemplo, derecho a ser oído en el juicio, necesidad de contradicción, o existencia de un principio mínimo de prueba). El art. 34.2 R. 44 opera como una excepción a la libre circulación de resoluciones y, por ello, no debería interpretarse extensivamente ni debería considerarse una ampliación por analogía, de modo que sólo pueden ser protegidos a través del art. 34.1 R. $44^{75}$.

Ahora bien, siendo cierto lo expuesto, no lo es menos que el empleo de la condición denegatoria del orden público vinculado al juego de la competencia judicial internacional del juez de origen no debe dejar la totalidad de las puertas cerradas. Piénsese, en este sentido, en el art. 35.3 R. 44, si bien extensibles estos argumentos también al art. 24 R. 2201.

La interpretación restrictiva a partir de la cual debe ser aplicada la prohibición del art. 35 R. 44 (también, art. 24 R. 2201) por parte de los operadores jurídicos de los Estados miembros ${ }^{76}$ supone: primero, limitar

TALLon, H., "Le Règlement no 1347/2000...", loc. cit., p. 410; o MAGnus, U./MANKowski, P. (ed.), European..., op. cit., p. 287.

${ }^{74}$ STJUE de 13 de octubre de 2011, As. C-139/10, Prism Investments BV v. Jaap Anne van der Meer. Al respecto, véanse DeVERS, A., "L'exequatur d'une décision déjà exécutée dans I'État member d'origine", La Semaine Juridique - édition générale, núm 4, 2012, pp. 152-155; IDOT, L., "Étendue du contrôle de l'exequatur!", Europe, Comm. núm. 12, Décembre 2011, p. 500. También es así en la práctica de Derecho autónomo español; por ejemplo, ATS de 23 de mayo de 2000 (RJ 2000\4382) y de 6 de junio de 2000 (RJ 2000\4653), que rechazaron la posibilidad de oponer al exequátur la alegación de prescripción vinculada a la acción causal; AAP Baleares de 14 de octubre de 2004 (JUR 2004\285896), respecto de la alegación del pago de la deuda contenida en una resolución judicial alemana como motivo de denegación; o AAP de valladolid de 22 de julio de 2008 (JUR 2008\353525), respecto de la imposibilidad de alegación de un motivo de denegación de exequatur distinto a los relacionados en los arts. 34 y 35 R. 44, aunque sí lo estaba en el (anterior) art. 954 LEC española (actual, art. 46 LCJI).

${ }^{75}$ Sobre ello, Fernández RozAS, J.C./SÁnCHEZ LORENZO, S., Derecho..., op. cit., 2018, p. 266. En la jurisprudencia comunitaria, STJUE de 28 de marzo de 2000, As. C-7/1998, Krombach, y la STJUE de 2 de abril de 2009, As. C-394/07, Gambazzi.

${ }^{76}$ En este sentido, respecto del art. 35 R. 44, HeSs, B./Pfeiffer, T./SChlosser, P. (ed.), The Brussels..., op. cit., 2008, par. 478; o O'MALLEY, S./LAYTON, A., European..., op. cit., p. 
el control de competencia del juez de origen a los casos señalados al efecto (competencias exclusivas, seguros y consumo, matizando el Reglamento 1215/2012 este control y ampliándolo a la materia laboral), en una suerte de numerus clausus de materias sujetas a examen ${ }^{77}$; segundo, no controlar la competencia del juez de origen respecto de materias no incluidas en ese numerus clausus; y, tercero, no ampliar el espectro de este control a partir de otras condiciones denegatorias de reconocimiento como el orden público (art. 35.3 R. 44; art. 24 R. 2201) ${ }^{78}$. No importa, a estos efectos, que el operador jurídico de un Estado UE haya aplicado incorrectamente las reglas de competencia del Reglamento 44/2001 (o Reglamento 2201/2003) a una situación privada comunitaria (art. 2 R. 44; art. 3 a 5 R. 2201) o que, enfrentado a una situación no comunitaria, haya basado su competencia, aun en aplicación correcta de las reglas de competencia, en un foro exorbitante (art. 4 R. 44; art. 7 R. 2201 , relativo a las competencia residuales) ${ }^{79}$.

No obstante, en relación con resoluciones de un Tribunal de la UE fundamentadas en un foro exorbitante, cabe la posibilidad de entender, a pesar de lo dispuesto en el art. 35.3 R. 44 (art. 24 R. 2201), que debería haber un límite a esta interpretación restrictiva. Ni el Reglamento 44/2001 (y Reglamento 1215/2012), como tampoco el Reglamento 2201/2003, deberían modificar los estándares constitucionalmente vigentes relativos a la tutela judicial efectiva en los Estados miembros (art. 24 Constitución española; art. $6 \mathrm{CEDH}$ ), lo que supondría que, cuando la declaración de la competencia del Tribunal de origen represente una carga abusiva e irrazonable sobre el demandado, tal como podría suceder, por ejemplo, cuando su vulneración haya derivado en la atribución de competencia a favor de un Tribunal de un Estado miembro sin una conexión significativa

732. Respecto del art. 24 R. 2201, Gaudemet-Tallon, H., "Le Règlement no 1347/2000...", loc. cit., pp. 410-411.

${ }^{77}$ Así, Carrascosa González, J., "Art. 28 CB", en A.L. Calvo Caravaca (dir.), Comentario al Convenio de Bruselas relativo a la competencia judicial y a la ejecución de resoluciones judiciales en materia civil y mercantil, Madrid, 1994, pp. 499-505, espec. p. 501; o Gothot, P./Holleaux, D., La Convención de Bruselas de 27 septiembre 1968, Madrid, 1986 (traducción española de La Convention de Bruxelles du 27 Septembre 1968 (Compètence judiciaire et effets des jugements dans la CEE), Paris, 1985), p. 192.

${ }^{78}$ En este sentido, en relación con el Reglamento 2201/2003, CHALAS, C., "Art. 24 R 2201", en CoRneloup, S. (dir.), Droit..., op. cit., pp. 402-403. En relación con el Reglamento 44/2001 (Reglamento 1215/2012), JENARD, P., "Informe...", loc. cit., p. 44; Calvo Caravaca, A.L./Carrascosa González, J., Derecho..., op. cit., vol. II., p. 301; Gaudemet-Tallon, H., Compétence..., op. cit., p. 506. Esta misma interpretación restrictiva del orden público del art. 34.1 R. 44 puede verse en la STJCE de 4 de febrero de 1988, As. C-145/86, Hoffmann v. Krieg, donde el TJUE, además de recordar que "...únicamente debe actuar en casos excepcionales...", entiende que "...queda excluido en todo caso cuando... el problema planteado es el de la compatibilidad de una resolución extranjera con una resolución nacional, problema que debe zanjarse con arreglo a la disposición específica recogida en el apartado 3 del art. 27 CB (posterior art. 34.3 R. 44 y actual art. 45 R. 1215)...".

${ }^{79}$ Virgós Soriano, M./Garcimartín Alférez, F.J., Derecho procesal...., op. cit., p. 613; en relación con Reglamento 44/2001; Chalas, C., "Art. 24 R 2201", en Corneloup, S. (dir.), Droit..., op. cit., p. 400. 
con el litigio (foro exorbitante, foros basados únicamente en vínculos del demandante con el foro, como los derivados del art. 3.a.5 y 6 R. 2201, fundamentados en la residencia de un año del demandante en el foro o de seis meses si es nacional...), el orden público no debería desactivarse por el tenor del art. 35.3 R. 44 (o art. 24 R. 2201) ${ }^{80}$. Téngase en cuenta que el TJUE estimó que, aunque el objetivo del Convenio (de Bruselas) es "...garantizar la simplificación de las formalidades a que están sometidos el reconocimiento y la ejecución recíprocos de las decisiones judiciales, este objetivo no puede, en todo caso, alcanzarse menoscabando los derechos de defensa..." 81 . Lo expuesto resultaría trasladable a una situación de litispendencia donde la vulneración de la regla reguladora conlleve una quiebra de la tutela del justiciable en relación con la protección de los derechos fundamentales 82 .

Repárese, al hilo de lo expuesto, en el art. 72 R. 44, reproducido en el art. 72 R. 1215, cuando establece que "...el presente Reglamento no afectará a los acuerdos por los que los Estados miembros, antes de la entrada en vigor del Reglamento (CE) n. 44/2001, se hubieran comprometido en virtud del artículo 59 del Convenio de Bruselas de 1968 a no reconocer una resolución dictada en otro Estado contratante del citado Convenio contra un demandado que tenga su domicilio o su residencia habitual en un tercer Estado cuando, en el caso previsto en el artículo 4 del citado Convenio, la resolución solo hubiera podido fundamentarse en un criterio de competencia contemplado en el artículo 3, apartado 2, de dicho Convenio (foros exorbitantes)...". También, si bien no reproducido en el Reglamento 2201/2003, en tanto que "...los acuerdos preexistentes están ya protegidos de conformidad con el artículo 307 del Tratado (actual art. 351 TFUE)..." 83 , el art. 16 R. 1347, que estimaba que "...los Tribunales de los Estados miembros, en virtud de un acuerdo sobre reconocimiento y ejecución de resoluciones judiciales, podrán no reconocer resoluciones

\footnotetext{
${ }^{80}$ De esta opinión, Virgós Soriano, M./Garcimartín AlfÉReZ, F.J., Derecho procesal...., op. cit., p. 613; Juenger, K., "La Convention de Bruxelles du 27 septembre 1968 et la courtoisie internationale. Réflexions d'un américain", Rev. cr. dr. int. pr., 1983, pp. 3751, espec. p. 42. Específicamente en materia de crisis matrimoniales, Ni SHúlLEABÁHIN, M., Cross-Border..., op. cit., pp. 221-224; o Grolimund, P., "Human rights and Jurisdiction: General Observations and Impact on the Doctrine of forum non conveniens and forum conveniens", European Journal of Law Reform, vol. 4, 2002, pp. 87-118, espec. pp. 94 y 116.

${ }^{81}$ Véase ap. 43 de la STJUE de 28 de marzo de 2000, As. C-7/1998, Krombach; también, ap. 10 de la STJCE de 11 de junio de 1985, As. C-49/84, Debaecker v. Plouvier. Es cierto, sin embargo, que, aunque el ap. 43 de la STJUE de 28 de marzo de 2000, As. C7/1998, Krombach, dice lo expuesto, su ap. 34 que, "...habida cuenta de la cláusula de orden público contenida en el artículo 27, número 1, del Convenio, el Tribunal del Estado requerido no puede tener en cuenta únicamente, frente a un demandado domiciliado en su territorio, el hecho de que el Tribunal del Estado de origen haya basado su competencia en la nacionalidad de la víctima de una infracción...". Sobre ello, CHALAS, C., "Art. 24 R 2201", en Corneloup, S. (dir.), Droit..., op. cit., p. 403.

${ }^{82}$ Se hace esta pregunta, ChalAs, C., "Art. 24 R. 2201", en Corneloup, S. (dir.), Droit..., op. cit., p. 404.

${ }^{83}$ Véase Propuesta de Reglamento del Consejo relativo a la competencia, el reconocimiento y la ejecución de resoluciones judiciales en materia matrimonial y de responsabilidad parental derogando el Reglamento (CE) no 1347/2000 y modificando el Reglamento (CE) no 44/2001 en materia de alimentos (COM/2002/0222 final).
} 
dictadas en otro Estado miembro que, en un caso de los previstos en el art. 8 , sólo pudieran fundamentarse en criterios de competencia distintos de los especificados en los arts. 2 a $7 . . .84$.

\subsection{2.- En su proyección desde el orden público procesal}

Aunque no entra en ello el TJUE, que se limita, como estamos viendo, a la interacción entre violación de las reglas de litispendencia y prohibición de control de competencia del juez de origen, plantea el órgano remitente, como adelantamos, si esta vulneración de las reglas de litispendencia atenta contra el orden público procesal del Estado requerido en tanto que menoscaba la función y finalidad de normas imperativas basadas en la confianza y lealtad procesal recíproca entre los Estados miembros como fundamento del reconocimiento recíproco de resoluciones judiciales.

La respuesta, en un primer momento, resulta negativa, en atención a los límites que la práctica del TJUE impone al concepto de orden público que define cada Estado miembro ${ }^{85}$.

Primero, porque, tal como opina el Abogado General, las reglas de litispendencia no tienen la consideración de norma jurídica esencial en el ordenamiento jurídico de un Estado miembro o de un derecho reconocido como fundamental en ese ordenamiento jurídico: el carácter de las normas reguladoras de la litispendencia no es comparable a las aplicadas por el TJUE a la hora de considerar que el reconocimiento de la resolución perjudicaría el orden público procesal de la UE ${ }^{86}$. Y es que, de acuerdo con esta práctica del TJUE, "...el art. 23.a R. 2201 debe interpretarse en el sentido de que, cuando no exista una violación manifiesta, habida cuenta del interés superior del menor, de una norma jurídica considerada esencial en el ordenamiento jurídico de un Estado miembro o de un derecho reconocido como fundamental en ese ordenamiento jurídico, dicha disposición no permite al órgano jurisdiccional de ese Estado miembro que se considera competente para resolver sobre la custodia de un menor denegar el reconocimiento de la resolución de un órgano jurisdiccional de otro Estado miembro que ha resuelto sobre la custodia de dicho menor..."87. O, lo que es lo mismo, "...sólo debería recurrirse a la cláusula de orden público que figura en el art. 23.a R. 2201 en el caso de que,

\footnotetext{
${ }^{84}$ Sobre ello, GAUdemet-TALLON, H., "Le Règlement no 1347/2000...", loc. cit., pp. 409-410; o Chalas, C., "Art. 24 R. 2201", en Corneloup, S. (dir.), Droit..., op. cit., pp. 400-401.

${ }^{85}$ En los ap. 39 y 40 de la STJUE de 25 de mayo de 2016, As. C-559/14, Meroni, se estima que "...aunque, en virtud de la reserva establecida en el art. 34.1 R. 44, los Estados miembros pueden, en principio, seguir determinando libremente, conforme a sus concepciones nacionales, las exigencias de su orden público, los límites de este concepto forman parte de la interpretación del Reglamento..." (ap. 39); "...por consiguiente, si bien no corresponde al Tribunal de Justicia definir el contenido del concepto de orden público de un Estado miembro, sí le corresponde controlar los límites dentro de los cuales los Tribunales de un Estado miembro pueden recurrir a este concepto para no reconocer una resolución dictada por un órgano jurisdiccional de otro Estado miembro..." (ap. 40). Véase, asimismo, ap. 56 y 58 de la STJCE de 28 de abril de 2009, As. C-420/07, Apostolides.

${ }^{86}$ Véase ap. 87 de las Conclusiones del Abogado General. Sobre este carácter, STJUE de 28 de marzo de 2000, As. C-7/1998, Krombach; la STJUE de 2 de abril de 2009, As. C394/07, Gambazzi; y la STJUE de 25 de mayo de 2016, As. C-559/14, Meroni.

${ }^{87}$ Véase ap. 53 de la STJUE de 19 de noviembre de 2015, As. C-455/15, P.
} 
habida cuenta del interés superior del menor, el reconocimiento de la resolución dictada en otro Estado miembro vulnerara de manera inaceptable el ordenamiento jurídico del Estado requerido, por menoscabar un principio fundamental. Para respetar la prohibición de revisión en cuanto al fondo de la resolución dictada en otro Estado miembro, prevista en el art. 26 R. 2201, el menoscabo debería constituir una violación manifiesta, habida cuenta del interés superior del menor, de una norma jurídica considerada esencial en el ordenamiento jurídico del Estado requerido o de un derecho reconocido como fundamental en este ordenamiento..." 88 .

Segundo, porque operar de esta manera, y, con ello, no hacer operativa la condición denegatoria del orden público, se ajusta a los principios antes aludidos que fundamentan el régimen de reconocimiento tanto en el Reglamento 2201/2003 como en el Reglamento 44/2001: carácter excepcional del recurso a la cláusula de orden público; prohibición de denegar el reconocimiento de una resolución extranjera procedente de otro Estado miembro con base en la aplicación incorrecta del Derecho de la UE. Téngase en cuenta que "...el principio de confianza mutua entre Estados miembros (...) obliga a cada uno de los Estados miembros, en particular en lo que se refiere al espacio de libertad, seguridad y justicia, a considerar, salvo en circunstancias excepcionales, que todos los demás Estados miembros respetan el Derecho de la Unión, y, muy especialmente, los derechos fundamentales reconocidos por ese Derecho..." 89 .

Es cierto que la falta de sanción de la infracción de una norma imperativa como la reguladora de la litispendencia, que recogen la práctica totalidad de reglamentos europeos, puede menoscabar el funcionamiento correcto de los distintos instrumentos comunitarios en materia de reconocimiento de resoluciones extranjeras. Más todavía en un contexto en el que el abanico tan amplio de foros de competencia que oferta el legislador comunitario favorece la instrumentalización de las normas de litispendencia, especialmente en caso de interposición de una demanda ante un órgano jurisdiccional de un Estado UE cuya legislación no permite solicitar el divorcio inmediatamente ${ }^{90}$. No obstante, existen ciertos

\footnotetext{
${ }^{88}$ Véase ap. 39 de la STJUE de 19 de noviembre de 2015, As. C-455/15, P.; y, por analogía, ap. 44 de la STJUE de 16 de julio de 2015, As. C-681/13, Diageo Brands.

${ }^{89}$ Véase ap. 40 de la STJUE de 16 de julio de 2015, As. C-681/13, Diageo Brands; también, ap. 45 de la STJUE de 23 de octubre de 2014, As. C-302/13, flyLAL-Lithuanian Airlines, donde, en relación con el Reglamento 44/2001, donde se afirma que "...dicho Reglamento está basado precisamente en la confianza recíproca en la justicia dentro de la Unión. Tal confianza exige, en particular, que las resoluciones judiciales dictadas en un Estado miembro sean reconocidas de pleno Derecho en otro Estado miembro...". Asimismo, Dictamen 2/13 del Tribunal de Justicia (Pleno) de 18 de diciembre de 2014 (http://curia.europa.eu/juris/document/document.jsf?docid=160882\&doclang=ES), ap. 191.

${ }^{90}$ Véanse ap. 88 y 89 de las Conclusiones del Abogado General. En relación con las tácticas dilatorias que derivan de la asimilación de la separación al divorcio y del retraso del tratamiento de la reclamación de divorcio resultante de la norma de litispendencia,
} 
mecanismos que pueden paliar estas consecuencias, más allá de la utilización fuera de sus límites de la cláusula del orden público. Por un lado, por la existencia de una importante jurisprudencia del TJUE orientando a los operadores jurídicos del funcionamiento y límites de las reglas de litispendencia, que disminuirá los casos de aplicación incorrecta en el futuro, especialmente en el ámbito del Derecho de familia presidido por el principio del interés superior del menor ${ }^{91}$. Por otro, por la existencia de mecanismos que favorecen la cooperación y diálogo entre órganos jurisdiccionales en orden a reducir los conflictos de procedimiento, en este caso, los relativos a la litispendencia. Sería el caso del art. 29.2 R. 1215 o los arts. 17 R. 2016/1103 y R. 2016/110492, el propio art. 15 R. 2201, o, incluso, la labor de la Red Judicial Europea en materia civil y mercantil a la hora de facilitar y acelerar la cooperación judicial en caso de aplicación de estas disposiciones en materia de litispendencia93. Finalmente, y además de la posibilidad de elevar ante el TJUE una cuestión prejudicial ${ }^{94}$, la Comisión siempre puede valorar la eventual interposición de un recurso

Bonomi, A., "La compétence...", loc. cit., pp. 528-530; MAgnus, U./MANKowski, P. (ed.), European..., op. cit., p. 231.

${ }^{91}$ Por ejemplo, véanse ap. 82 a 84 de la STJUE de 9 de noviembre de 2010, As. C$296 / 10$, Purrucker, respecto de la utilización del principio del interés superior del menor a la hora de fijar los límites para la suspensión del procedimiento por razón de litispendencia en caso de falta de respuesta del órgano jurisdiccional ante el que se interpuso la primera demanda. Lo mismo, ap. 43 de la STJUE de 27 de octubre de 2016, As. C-428/15, D., sobre este principio proyectado sobre el art. 15 R. 2201, cuya aplicabilidad es de oficio o a instancia de parte. En el caso que nos ocupa, llama la atención al Abogado General (ap. 93, nota núm. 70) que, respecto de un menor nacido en febrero de 2006 y que vive en Rumanía desde octubre de 2006, el procedimiento siga pendiente en Italia después de once años (interpuesta la primera demanda en mayo de 2007, la primera resolución de fondo se dictó en julio de 2013 tras ordenar el traslado del caso en enero de 2012) y que el litigio versa sobre el reconocimiento de la sentencia dictada en Rumania, que adquirió firmeza después de cinco años (12 de junio de 2013).

${ }^{92}$ Véase ap. 81 de la STJCE de 9 de noviembre de 2010, As. C-296/10, Purrucker, cuando hace mención a que, "...según las posibilidades previstas por su Derecho nacional, cuando los dos litigios enfrenten a las mismas partes, el segundo órgano jurisdiccional podrá interrogar a la parte que propone la excepción de litispendencia acerca de la existencia del litigio alegado y del contenido de la demanda. Por otra parte, teniendo en cuenta que el Reglamento 2201/2003 se fundamenta sobre la cooperación y la confianza mutua entre órganos jurisdiccionales, este órgano jurisdiccional podrá advertir al primero de que ante él se ha interpuesto una demanda, llamar la atención de este último sobre la eventualidad de una litispendencia, invitarlo a que le informe acerca de la demanda pendiente ante él y a que se pronuncie acerca de su competencia, en el sentido del Reglamento 2201/2003, o le comunique toda resolución ya adoptada a este respecto. Finalmente, el órgano jurisdiccional ante el que se plantea el asunto en segundo lugar podrá dirigirse a la autoridad central de su Estado miembro...".

${ }^{93}$ Véanse ap. 50, 90 a 92 de las Conclusiones del Abogado General.

${ }^{94}$ Véase ap. 47 de la STJUE de 25 de mayo de 2016, As. C-559/14, Meroni, cuando dice que "...esta confianza que los Estados miembros otorgan mutuamente a sus sistemas jurídicos y a sus instituciones judiciales es la que permite considerar que, en caso de aplicación errónea del Derecho nacional o del Derecho de la Unión, el sistema de recursos establecido en cada Estado miembro, completado por el mecanismo de remisión prejudicial regulado en el art. 267 TFUE, proporciona a los justiciables una garantía suficiente..."; también, ap. 63 de la STJUE de 16 de julio de 2015, As. C-681/13, Diageo Brands, en parecidos términos. 
por incumplimiento en caso de aplicación errónea del Derecho autónomo o del Derecho de la UE y de fallo en el sistema de recursos establecido en cada Estado miembro95.

Por todo ello, no debería tener cabida el empleo general de la condición denegatoria del orden público con base en la vulneración de las reglas reguladoras de la litispendencia intracomunitaria96.

Con todo, que se sostenga la imposibilidad de utilización general de la condición denegatoria de orden público por causa de infracción de las reglas de la litispendencia no debería significar una prohibición absoluta y en todo caso de su empleo. Por un lado, porque, siendo importantes los mecanismos referidos en orden a evitar/paliar/corregir las consecuencias de una aplicación incorrecta del Derecho de la UE, no tienen por qué ser necesariamente adecuados y suficientes en orden a la protección efectiva de los derechos fundamentales, además de incompatibles con otras opciones. Por otro, porque, sin desconocer el carácter excepcional de la cláusula de orden público, su interpretación restrictiva y la naturaleza de los derechos que protege, no debería descartarse la existencia de circunstancias excepcionales cuya confluencia sí podría justificar la invocación del motivo de denegación del reconocimiento basado en el orden público del Estado miembro requerido, que prevé los derechos fundamentales reconocidos por el Derecho de la UE. Sería el caso de infracción de las normas de litispendencia resultante del desconocimiento de los Reglamentos aplicables y de la jurisprudencia del TJUE; o de haber dado lugar a la vulneración de derechos procesales de valor superior como aquéllos que, por ejemplo, garantizan la expresión de las alegaciones del progenitor en cuyo domicilio no reside el menor, así como la observancia de plazos de enjuiciamiento razonables ${ }^{97}$. Desde esta óptica, el error de Derecho alegado vendría a conformar "...una infracción manifiesta de una norma jurídica considerada esencial en el ordenamiento jurídico de la Unión y, por tanto, en el del Estado miembro requerido o de un derecho reconocido como fundamental en esos ordenamientos jurídicos..." ${ }^{\prime 98}$.

\footnotetext{
${ }^{95}$ Véase ap. 55 de la STJUE de 16 de julio de 2015, As. C-681/13, Diageo Brands.

${ }^{96}$ Como indica Álvarez González, S., "Litispendencia...", loc. cit., par. 1, "...el valor añadido de la sentencia radica en que el orden público del Estado requerido (y su respeto sí es una condición de reconocimiento) no puede ser alegado para canalizarla (la infracción de las reglas de litispendencia)...; el TJ no lo había fijado expresamente con anterioridad y la estricta letra de la ley tampoco...".

${ }^{97}$ Véase ap. 94 de las Conclusiones del Abogado General, sosteniendo esta aplicación excepcional de la cláusula de orden público por infracción de las reglas de litispendencia. Al respecto, téngase en cuenta, asimismo, ap. 44 de la STJCE de marzo de 2000, As. C$7 / 98$, Krombach, cuando entiende que "...la aplicación de la cláusula del orden público es posible en los casos excepcionales en los que las garantías establecidas en la legislación del Estado de origen y en el propio Convenio (de Bruselas de 1968) no bastan para proteger al demandado de una violación manifiesta de su derecho a defenderse ante el Tribunal de origen, tal como está reconocido por el [Convenio Europeo para la Protección de los Derechos Humanos y de las Libertades Fundamentales, firmado en Roma el 4 de noviembre de 1950]..."; también ap. 44 a 46 de la STJUE de 25 de mayo de 2016, As. C559/14, Meroni.

${ }^{98}$ Véase ap. 68 de la STJUE de 16 de julio de 2015, As. C-681/13, Diageo Brands; también, ap. 39 y 53 de la STJUE de 19 de noviembre de 2015, As. C-455/15, P.
} 
Recuérdese que, en el caso que nos ocupa, el TJUE considera que la vulneración de las reglas reguladoras de la litispendencia intracomunitaria no tiene cabida en la condición denegatoria general del orden público de conformar esta circunstancia la única razón que pretende fundamentarlo. De ahí que la resolución comentada se hable de imposibilidad de que "...los órganos jurisdiccionales del Estado miembro del que forma parte el órgano jurisdiccional ante el que se presentó la primera demanda denieguen, por esta sola razón, el reconocimiento de dicha resolución. En particular, esta violación no puede justificar, por sí sola, la denegación del reconocimiento de dicha resolución por ser manifiestamente contraria al orden público de este Estado miembro..." (FD 56).

\section{4.- CONCLUSIONES}

En el ámbito del espacio judicial europeo y como no podía ser de otra manera, una eventual infracción de las reglas de litispendencia por parte del Tribunal de origen que dictó aquella resolución que pretende ahora reconocerse en otro Estado miembro no constituye causa de denegación de reconocimiento. Era ésta la respuesta esperable del TJUE a la cuestión prejudicial y así fue la respuesta emitida por el TJUE a través de esta resolución. Si nada hay que decir respecto del ajuste de esta conclusión a la normativa y estructura del Reglamento 2201/2003, régimen en vigor en el momento de elevar la cuestión prejudicial, menos lo habrá a partir de la aplicación del Reglamento (UE) 2019/1111, del Consejo, de 25 de junio de 2019, relativo a la competencia, el reconocimiento y la ejecución de resoluciones en materia matrimonial y de responsabilidad parental, $y$ sobre la sustracción internacional de menores (versión refundida) ${ }^{99}$, que sustituirá al Reglamento 2201/2003 desde el 01 de agosto de 2022, al estimar, ya expresamente, que "...el reconocimiento de una resolución únicamente debe denegarse en caso de que concurran uno o varios de los motivos de denegación del reconocimiento previstos en el presente Reglamento. La lista de los motivos de denegación del reconocimiento en el presente Reglamento es exhaustiva. No debe ser posible alegar como motivo de denegación los motivos que no se encuentran enumerados en el presente Reglamento, como, por ejemplo, la vulneración de la norma de litispendencia..." (Considerando núm. 56 R. 2019).

\section{5.- BIBLIOGRAPHY}

ÁlvAREZ GonZÁLEZ, S., "El Reglamento 4/2009/CE sobre obligaciones alimenticias: cuestiones escogidas", Diario La Ley, núm. 7230, 31 de julio de 2009, pp. $1-21$.

\footnotetext{
${ }^{99}$ Reglamento (UE) 2019/1111, del Consejo, de 25 de junio de 2019, relativo a la competencia, el reconocimiento y la ejecución de resoluciones en materia matrimonial y de responsabilidad parental, y sobre la sustracción internacional de menores (versión refundida) (DOCE L 178/1, de 02 de julio de 2019), que deroga el Reglamento $2201 / 2003$ (art. 104 R. 2019) y que resulta aplicable a partir del 01 de agosto de 2022 (art. 105 R. 2019).
} 
Álvarez GonzÁlez, S., Crisis matrimoniales internacionales y prestaciones alimenticias entre cónyuges, Madrid, 1996.

Álvarez GonzÁlez, S., "Litispendencia, reconocimiento y orden público (comentario breve a la Sentencia del Tribunal de Justicia de 16 de enero de 2019, Asunto C-386/17: Liberato), La Ley (Unión Europea), 29 de marzo de 2019, pp. 1-11.

ANCEL, B./MUIR WATT, H., "La désunion européenne: le Règlement dit Bruxelles II", Rev. cr. dr. int. pr., 2001, pp. 403-457.

BONOMI, A., "La compétence internationale en matière de divorce, quelques suggestions pour une (improbable) révision du règlement Bruxelles II bis", Rev. cr. dr. int. pr., 2017, pp. 511-534.

BORRÁs RODRÍGUEZ, A., "Informe explicativo del Convenio celebrado con arreglo al artículo K.3 del Tratado de la Unión Europea, sobre la competencia, el reconocimiento y la ejecución de resoluciones judiciales en materia matrimonial", DOCE de 16 de julio de 1998, C 221, p. 27.

Calvo Caravaca, A.L./Carrascosa GonzÁlez, J., Derecho internacional privado, vol, II, 15a ed., Comares, Granada, 2014/2015.

Calvo Caravaca, A.L./Carrascosa González, J., Derecho internacional privado, $18^{a}$ ed., vol. I, 2018.

CAMPUZANO DÍAZ, B., "Uniform conflicts of law rules on divorce and legal separation via enhanced cooperation", en CAMPUZANO DÍAZ, B./CZEPELAK, M./ROdRÍGUeZ BENOT, A./ROdRÍGUEZ VÁZQUEZ, A. (eds.), Latest developments in EU Private International Law, Intersentia, CambridgeAntwerp-Portland, 2011, pp. 23-48.

CANO BAZAGA, E., "El Derecho de familia comunitario: competencia judicial internacional de los Tribunales españoles en materia de crisis matrimoniales y responsabilidad parental", Anuario de Derecho Europeo, núm. 2, 2002, pp. 67-89.

CARO GÁNDARA, R., "Nuevos desafíos comunitarios en materia matrimonial y de responsabilidad parental en las relaciones jurídicas transfronterizas (competencia judicial internacional, reconocimiento y ejecución de resoluciones en materia de familia y sustracción internacional de menores a la luz del Reglamento 2201/2003)", Estudios Jurídicos, 2004, pp. 46954731.

Carrascosa González, J., "Art. 28 CB", en Calvo Caravaca, A.l. (dir.), Comentario al Convenio de Bruselas relativo a la competencia judicial y a la ejecución de resoluciones judiciales en materia civil y mercantil, Madrid, 1994, pp. 499-505.

CORNEloup, S. (dir.), Droit européen du divorce. European Divorce Law, Université de Bourgogne, Lexis Nexis, Paris, 2013.

De Miguel Asensio, P., "Espacio europeo de justicia: evolución y perspectivas en el sector del reconocimiento y ejecución de decisiones", AEDIPr., 2006, pp. 441-466.

DEVERS, A., "L'exequatur d'une décision déjà exécutée dans l'État member d'origine", La Semaine Juridique - édition générale, núm 4, 2012, pp. 152155.

DiCKINSON, A./LEIN, E. (ed.), The Brussels I Regulation Recast, Oxford, 2015.

DURÁN AYAGO, A., "Europeización del Derecho internacional privado: del Convenio de Bruselas de 1968 al Reglamento (UE) 1215/2012. Notas sobre el proceso de construcción de un espacio judicial europeo", Revista General del Derecho Europeo, vol. 29, 2013, pp. 1-55. 
FERNÁNDEZ ROZAS, J.C./SÁNCHEZ LORENZO, S., Derecho internacional privado, 10a ed., Civitas, Thomson Reuters, Madrid, 2018.

FERNÁNDEZ ROZAS, J.C./SÁNCHEZ LORENZO, S., Derecho internacional privado, 8a ed., Civitas, Thomson Reuters, Madrid, 2015.

GaRdeÑES SANTIAGO, M., "Litispendencia y cosa juzgada en el extranjero ante la nueva LEC", AEDIPr., 2001, pp. 315-337.

GaRdeÑES SANTIAGO, M., "Procedimientos paralelos en España y en el extranjero: el Título IV de la Ley 29/2017 (arts. 37 a 40)", REDI, vol. LXVIII, 2016-I, pp. 109-119.

GASCÓN INCHAUSTI, F., "Reconocimiento y ejecución de resoluciones judiciales extranjeras en la Ley de cooperación jurídica internacional en materia civil", Cuadernos de Derecho Transnacional, núm. 2, 2015, pp. 158-187.

GAUDEMET-TALLON, H., "Divorce - Divorce prononcé en France - Introduction Compétence des tribunaux français - Particularités de l'instance", JurisClasseur - Droit international, fascículo 547-10, marzo de 2017.

GAUDEMET-TALLON, H., "Le Règlement no 1347/2000 du Conseil du 29 mai 2000: «Compétence, reconnaissance et exécution des décisions en matiere matrimoniale et en matiere de responsabilité parentale des enfants communs»", Journ. dr. int., 2001-II, pp. 381-430.

GaUdemet-TALlon, H., Compétence et exécution des jugements en Europe (matières civile et commerciale: Règlements 44/2001 et 1215/2012, Conventions de Bruxelles 1968 et de Lugano 1988 et 2007), 5a ed., LGDJ, 2015.

Gothot, P./HolleauX, D., La Convención de Bruselas de 27 septiembre 1968, Madrid, 1986 (traducción española de La Convention de Bruxelles du 27 Septembre 1968 (Compètence judiciaire et effets des jugements dans la CEE), Paris, 1985).

Grolimund, P., "Human rights and Jurisdiction: General Observations and Impact on the Doctrine of forum non conveniens and forum conveniens", European Journal of Law Reform, vol. 4, 2002, pp. 87-118.

GUZMÁN PECES, M., "Cuestiones problemáticas en torno a la litispendencia en el Reglamento (UE) $2201 / 2003$ en el ámbito de las crisis familiares", La Ley (Unión Europea), de 28 de febrero de 2019, pp. 1-17.

Hess, B./Pfeiffer, T./SChlosser, P., The Brussels I Regulation 44/2001, 2008.

HODSON, D., A practical guide to International Family Law, Bristol, Family Law, 2008.

IDOT, L., "Étendue du contrôle de l'exequatur!", Europe, Comm. núm. 12, Décembre 2011, p. 500.

JENARD, P., "Informe sobre el Convenio de 27 de septiembre de 1968 relativo a la competencia judicial y a la ejecución de resoluciones judiciales en materia civil y mercantil" (Informe JENARD), DOCE C 189, 28 de julio de 1990.

JUENGER, K., "La Convention de Bruxelles du 27 septembre 1968 et la courtoisie internationale. Réflexions d'un américain", Rev. cr. dr. int. pr., 1983, pp. 37-51.

KAYE, P., Civil jurisdiction and enforcement of foreign judgements, 1987.

MAGNuS, U./MANKOWSKI, P. (ed.), European Commentaries on Private International Law ECPIL: Brussels II bis Regulation, Sellier, Munich, 2012.

Mosconi, F., "Giurisdizione e riconoscimento delle decisioni in materia matrimoniale secondo il Regolamento comunitario del 29 maggio 2000", Rivista di diritto processuale, núm. 2, 2001, pp. 376-408.

Ni ShúlleabÁHIN, M., Cross-Border Divorce Law. Bruxelles II bis, Oxford University Press, 2010. 
O’MALleY, S./LAYTON, A., European civil practice, London, 1989.

PALAO MORENO, G., "Crisis matrimoniales internacionales y autonomía de la voluntad", Cursos de Derecho internacional y Relaciones internacionales de Vitoria-Gasteiz 2013, Aranzadi, Cizur Menor, 2014, pp. 451-531.

QUIÑONES ESCÁMEZ, A., "Nuevas normas comunitarias en materia de responsabilidad parental (Reglamento (CE) no 2201/2003 del Consejo, de 27.11.2003)", Indret, núm. 4, 2004.

REMIRO BROTÓNS, A., Ejecución de sentencias extranjeras en España (la jurisprudencia del Tribunal Supremo), Tecnos, Madrid, 1974.

REQUEJO ISIDRO, M., "Regulation (EC) 2201/03 and its personal scope. ECJ, November 29, 2007 Case C-68/07, Sundelind López", Yearbook of Private International Law, 2008, pp. 579-591.

RODRÍGUEZ VÁZQUEZ, M.A., "La regulación del Reglamento 4/2009 en materia de obligaciones de alimentos: competencia judicial internacional, ley aplicable y reconocimiento y ejecución de sentencias", reei.org, vol. 19, 2010, pp. $1-30$.

SÁnCHeZ JimÉnez, M.A., "Art. 29 CB", en Calvo CaravacA, A.L. (dir.), Comentario al Convenio de Bruselas relativo a la competencia judicial y a la ejecución de resoluciones judiciales en materia civil y mercantil, Madrid, 1994, pp. 506-514.

SÁNCHEZ JimÉnEZ, M.A., El divorcio internacional en la Unión Europea (jurisdicción y ley aplicable), Cizur Menor (Navarra), Aranzadi Thomson Reuters, 2013.

SÁNCHEZ LORENZO, S., "Competencia judicial y reconocimiento y ejecución de decisiones en materia civil y mercantil: del Convenio de Bruselas al Reglamento Bruselas I", en Cooperación jurídica internacional en materia civil. El Convenio de Bruselas, BORRÁs RODRÍGueZ, A. (dir.), Cuadernos de Derecho Judicial, 2001-IV, CGPJ, Madrid, 2001, pp. 181-228.

Virgós Soriano, M./GARCIMARTÍn AlfÉREZ, F.J., Derecho procesal civil internacional (litigación internacional), 2a ed., Madrid, 2007. 